\title{
Characterization of Spray A flame structure for parametric variations in ECN constant-volume vessels using chemiluminescence and laser-induced fluorescence
}

\author{
Noud Maes ${ }^{\mathrm{a}, *}$, Maarten Meijer ${ }^{\mathrm{a}}$, Nico Dam $^{\mathrm{a}}$, Bart Somers ${ }^{\mathrm{a}}$, Hubert Baya \\ Toda $^{\mathrm{b}}$, Gilles Bruneaux ${ }^{\mathrm{b}}$, Scott A. Skeen ${ }^{\mathrm{c}}$, Lyle M. Pickett ${ }^{\mathrm{c}}$, Julien Manin ${ }^{\mathrm{c}}$ \\ ${ }^{a}$ Department of Mechanical Engineering, Eindhoven University of Technology, P.O. Box \\ 513, 5600 MB Eindhoven, The Netherlands \\ ${ }^{b}$ IFP Energies nouvelles, 92852 Rueil-Malmaison Cedex, France \\ ${ }^{c}$ Combustion Research Facility, Sandia National Laboratories, P.O. Box 969, MS 9053, \\ Livermore, CA 94551, USA
}

\begin{abstract}
The transient and quasi-steady flame structure of reacting fuel sprays produced by single-hole injectors has been studied using chemiluminescence imaging and Planar Laser-Induced Fluorescence (PLIF) in various constant-volume facilities at different research institutes participating in the Engine Combustion Network (ECN). The evolution of the high-temperature flame has been followed based on chemiluminescence imaging of the excited-state hydroxyl radical $\left(\mathrm{OH}^{*}\right)$, and PLIF of ground-state $\mathrm{OH}$. Regions associated with low-temperature chemical reactions are visualized using formaldehyde $\left(\mathrm{CH}_{2} \mathrm{O}\right)$ PLIF with 355-nm excitation. We compare the results obtained by different research institutes under nominally identical experimental conditions and fuel injectors. In spite of design differences among the various experimental facilities, the results are consistent. This lends confidence to studies of transient behavior and parameter variations performed by individual research groups. We present results of the transient flame structures at Spray A reference conditions, and include parametric variations around this baseline, involving ambient temperature, oxygen concentration and injection pressure. Key results are the observed influence of an entrainment wave on the transient flame behavior, model-substantiated explanations for the high-intensity $\mathrm{OH}^{*}$ lobes at the lift-off length and differences with OH PLIF, and a general analogy of the flame structures with a spray cone along which the flame tends to locate for the applied parametric variations.
\end{abstract}

Keywords: Engine Combustion Network (ECN), Constant-volume vessel, Laser-induced fluorescence, Chemiluminescence, Flame structures, Spray A

\footnotetext{
* Corresponding author

Email address: n.c.j.maes@tue.nl (Noud Maes)
}

Preprint submitted to Combustion and Flame

August 31, 2016

(C) 2016. This manuscript version is made available under the Elsevier user license http://www.elsevier.com/open-access/userlicense/1.0/ 


\section{Introduction}

In order to achieve a concurrent reduction of fuel consumption and emission formation in compression ignition engines, a concerted optimization of engine, fuel and combustion concept will be essential. For such an optimization, a detailed understanding of the reacting fuel spray under high-pressure and hightemperature conditions is indispensable. Key to this understanding, is the effect of boundary conditions on the mixing of fuel and air, evaporation, and combustion processes in compression ignition engines. Alongside with the understanding of relevant processes, the development of future engines is to an increasing extent based on computational models, which require reliable and reproducible experimental results of well-defined test cases, to verify the sensitivities and assumptions of these models.

The Engine Combustion Network (ECN) is an international collaboration in the field of engine combustion research, which has acknowledged both the necessity of experimental and computational contributions supporting each other, as well as the need to pay due attention to experimental boundary conditions, so as to obtain consistency of experimental results [1]. To allow a direct comparison between experimental results obtained in different setups, guidelines for operation of the facilities as well as diagnostic techniques and post-processing standards have been established. Several combustion vessels in research institutes around the world have proven to be capable of reaching the predefined reference conditions, using nominally identical injectors, but with different auxiliary equipment. The validation of these conditions is based on pressure and temperature measurements, as well as characteristic parameters of sprays, such as the liquid length, vapor penetration, and Flame Lift-Off Length (FLOL) [2-4]. Such validation will lend credit to subsequent studies of parametric variations by individual contributing institutes, allowing an efficient expansion of the online data archive of the ECN. In the sequence of collaborative ECN publications, the first publication has illustrated the challenges involved when trying to match boundary conditions of different experimental facilities, despite reasonable agreement in spray penetration, ignition and combustion [2]. Subsequently, the characterization of boundary conditions is evaluated in detail for more experimental facilities, and the sensitivity of variations is quantified [3]. Overcoming variability between facilities has revealed the need to align procedures in diagnostic techniques as well as processing methods to obtain good agreement in comparisons of spray development, vaporization and combustion [4]. In an additional collaborative publication, differences in nozzle geometry and hydraulic behavior are revealed, giving rise to related parameters downstream of the injector orifice [5]. More recently, soot formation was studied extensively, including both experimental and numerical comparisons [6]. The detailed and structured approach of the ECN has also given rise to several publications on numerical combustion modeling [7-11].

This paper discusses characteristic structures that are found in the vicinity of a reacting spray flame. Following the evaporation of liquid fuel under engine-like conditions, low-temperature reactions initiate the fuel decomposi- 
tion into smaller hydrocarbons, which are subsequently consumed in the hightemperature reactions. Spectroscopic techniques are well-known and extensively employed to characterize reacting sprays relevant for internal combustion engines. Over the past decades, this has resulted in a basic understanding of the main processes which govern combustion, and allows identification of species related to low- and high-temperature reactions in a reacting fuel spray, such as $\mathrm{CH}_{2} \mathrm{O}$ and $\mathrm{OH}$, respectively [12-18]. In this work, Spray A results are presented, which have been obtained using various optical diagnostic techniques at IFPEn, Sandia and TU/e. The purpose of these measurements is a robust characterization of flame structures by the reproducibility of results between different contributing institutes, and the study of qualitative effects by variation in single parameters for a reacting fuel spray. Transient spray behavior is studied in more detail using high-speed cameras for chemiluminescence imaging and various timings for PLIF measurements, which allows an analysis of processes before and after the quasi-steady period of a lifted spray flame. Using yet available spray parameters from the ECN, regions with different reaction products are interpreted. We study the early development of the spatial distribution of chemical species characteristic for the transient initial phase. With this information, the Spray A characterization is expanded by means of parametric variations, identifying a general spray cone to describe the radial location of the flame.

\section{Experimental setups and conditions}

\subsection{Constant-volume combustion vessels}

The constant-volume vessels of IFPEn, Sandia and TU/e use a so-called preburn approach to achieve the desired thermodynamic conditions, as originally proposed by Oren [19]. The pre-burn approach is based on burning a lean charge in a constant volume to create a high-pressure and high-temperature ambient. After spark-ignition of the pre-burn mixture, the temperature and pressure in the vessel rapidly increase. At some time during the relatively long cool-down period, governed by heat loss to the vessel walls, the desired conditions will be met and fuel is injected. Differences and similarities between the combustion vessels which are used for contributing to the ECN have been described in detail in previous work $[2-5,20]$. In these studies, the operation of the combustion vessels has been discussed, followed by characterization of the ambient condition and injectors. Subsequently, these studies describe the liquid and spray penetration and combustion phenomena, defining characteristic time and length scales such as the ignition delay, liquid length, FLOL and

flame length. Ongoing research concerns parametric variations of the baseline condition, and more detailed studies related to the (reacting) fuel spray [21-25].

\subsection{ECN Spray A operating conditions and parametric variations}

The primary reference condition defined by the ECN, designated as "Spray A," features a spray of n-dodecane $\left(\mathrm{C}_{12} \mathrm{H}_{26}\right)$ from a single-hole diesel fuel injector $(90 \mu \mathrm{m})$ at an injection pressure of $150 \mathrm{MPa}$. The ambient conditions 
target the low-temperature combustion regime with a moderate amount of EGR $\left(900 \mathrm{~K}, 22.8 \mathrm{~kg} / \mathrm{m}^{3}\right.$, and $\left.15 \mathrm{vol} . \% \mathrm{O}_{2}\right)$, which is summarized together with the parametric variations applied in this work in Table 1 [1]. A batch of nominally identical ECN injectors is available to provide the growing number of participating institutes with appropriate hardware, and to cope with finite injector lifetime [26]. The injectors used in this work are identified with the numbers \#201001 (TU/e), \#210678 (IFPEn) and \#120370 (Sandia) [1]. Due to the focus of this work on the flame structure of the fuel spray, a longer injection duration than the usual $1.5 \mathrm{~ms}$ has been applied. Note that this should not influence the behavior of a spray around the FLOL due to the quasi-steadiness in this region during injection. Unless stated otherwise, the experimental results presented in this work are newly reported and consist of ensemble averages based on 5 to 20 individual recordings or experiments.

Table 1: Summary of the Spray A conditions with parametric variations. Spray A baseline conditions are indicated by bold text.

\begin{tabular}{lccc}
\hline Gas temperature $(\mathrm{K})$ & 800 & $\mathbf{9 0 0}$ & 1000 \\
Gas density $\left(\mathrm{kg} / \mathrm{m}^{3}\right)$ & \multicolumn{3}{c}{$\mathbf{2 2 . 8}$} \\
Oxygen (vol\%) & 13 & $\mathbf{1 5}$ & 21 \\
Injection pressure (MPa) & 50 & 100 & $\mathbf{1 5 0}$ \\
Fuel & \multicolumn{3}{c}{$\mathbf{C}_{12} \mathbf{H}_{26}$} \\
Fuel temperature $(\mathrm{K})$ & \multicolumn{3}{c}{$\mathbf{3 6 3}$} \\
\hline
\end{tabular}

In former studies, the conditions within the TU/e combustion vessel have been validated for the Spray A test case [3, 27]. After the previous ECN campaign [20], the vessel has been updated and new software for the control of the vessel was implemented. Subsequently, high-speed $\mathrm{OH}^{*}$ experiments of the previous campaign were reproduced with the new equipment and the results were used to validate the conditions based on the FLOL. As the FLOL is rather sensitive to the ambient [13-15], it served as a primary reference for the boundary conditions. After completion of the measurement campaign that produced the data to be discussed here, two small and counteracting deviations from the desired ambient conditions were discovered in the TU/e setup. A software error in the pre-burn charge filling procedure resulted in too high oxygen concentration, which was offset by an over-performing mixing fan which decreased the vessel core temperature. This simultaneous malfunctioning of two parts of the equipment went unnoticed, because their net effect on the spray flame structure essentially cancels. The resulting boundary conditions caused by both deviations add up to an ambient density of $23.7 \mathrm{~kg} / \mathrm{m}^{3}$, an ambient temperature of $870 \mathrm{~K}$ and an oxygen concentration of $16.9 \%$. These deviations remained constant over the entire measurement campaign of TU/e experiments.

\section{Optical diagnostic techniques}

Chemiluminescence of the excited-state hydroxyl radical $\left(\mathrm{OH}^{*}\right)$ and PLIF of ground-state $\mathrm{OH}$ and/or formaldehyde have been recorded in three different 
combustion vessels. A schematic overview of the generic optical setup is shown in Figure 1.

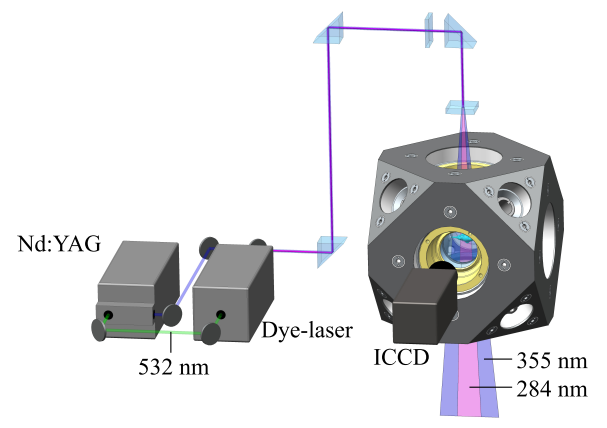

Figure 1: Schematic overview of the TU/e combustion vessel with the applied layout for detecting chemiluminescence and PLIF.

\subsection{Chemiluminescence}

High-speed image series and single-shot images of reacting fuel spray chemiluminescence have been obtained using intensified cameras equipped with spectral filters centered near the 307.8-nm peak emission line of the excited-state hydroxyl radical $(310 \pm 5 \mathrm{~nm})$. The $\mathrm{OH}^{*}$ radical is an excellent marker for the flame front location, since it is predominantly formed in the hot diffusion flame [28]. This results in a narrow region of excited radicals at the location of the flame front [29]. Table 2 lists the most important differences between the optical imaging systems which have been used to detect $\mathrm{OH}^{*}$. IFPEn used an intensified CCD camera (Princeton Instruments, PI-MAX2, RB slow intensifier) equipped with a Sodern lens (CERCO $45.5 \mathrm{~mm} \mathrm{f} / 1.8)$ and captured the reacting fuel spray during a quasi-steady state with a 2.5 -ms exposure time and a Semrock band-pass filter set centered around $315 \mathrm{~nm}$. Sandia used an intensified CCD camera (Princeton Instruments, PI-MAX3, UV intensifier) with an Nikon lens (UV Nikkor $105 \mathrm{~mm} \mathrm{f/4.5)} \mathrm{in} \mathrm{a} \mathrm{similar} \mathrm{fashion} \mathrm{to} \mathrm{IFPEn} \mathrm{and} \mathrm{imaged} \mathrm{the}$ spray flame with a band-pass filter centered around $308 \mathrm{~nm}$ (10 nm FWHM). In addition to this, a single high-speed movie ( $20 \mathrm{kHz}$ with a 2 - $\mu$ s exposure time) was recorded using a high-speed intensified camera with fiber-optic coupling, and the same UV-sensitive lenses and filters [30]. TU/e used a high-speed (10 \& $15 \mathrm{kHz}$ ) fiber-coupled intensified CMOS camera (Lambert HiCam, S20 photocathode) with a 10- $\mu$ s exposure time and a Nikon lens (UV Nikkor $105 \mathrm{~mm}$ f/4.5) with an Andover band-pass filter at $307 \mathrm{~nm}$. To produce the classical quasi-steady chemiluminescence images, illustrated in Figure 2, TU/e results are averaged during a period of $2.9 \mathrm{~ms}$, from $1.1 \mathrm{~ms}$ to $4 \mathrm{~ms}$ after Start Of Injection (SOI).

When fuel is injected in a Spray A experiment, liquid fuel breaks up into smaller droplets, vaporizes, and entrains enough hot air to initiate the combustion processes. After ignition, the flame front arises at a well-defined distance 


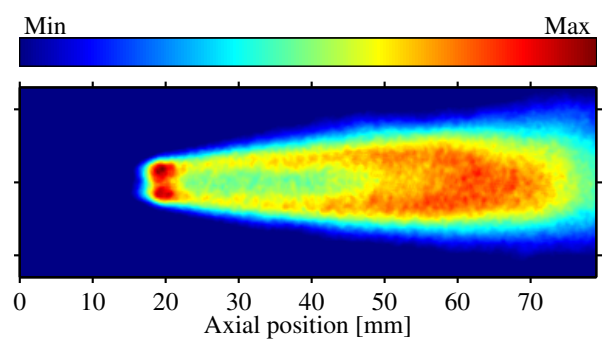

Figure 2: Example of a time-averaged, quasi-steady $\mathrm{OH}^{*}$ result at the Spray A baseline, obtained by $\mathrm{TU} / \mathrm{e}$ in a false-color scale. These are line-of-sight data and not Abel-inverted. The axial position corresponds to the downstream distance from the nozzle exit. The color scale is indicated at the top. Unless stated otherwise, this scale is used throughout the entire paper.

Table 2: $\mathrm{OH}^{*}$ chemiluminescence, $\mathrm{OH}$ PLIF and $\mathrm{CH}_{2} \mathrm{O}$ imaging system details. The values in the filter column represent the central wavelength with the full width at half maximum between parentheses.

\begin{tabular}{llccccc}
\hline & Species & Intensifier & Lens & Exposure & Pixel size & Filters \\
\hline IFPEn & $\mathrm{OH}^{*}$ & RB Slow & $45.5 \mathrm{~mm} \mathrm{f} / 1.8$ & $2.5 \mathrm{~ms}$ & $10.29 \mathrm{pixel} / \mathrm{mm}$ & $315 \mathrm{~nm}(25 \mathrm{n}$ \\
TU/e & $\mathrm{OH}^{*}$ & S20 & $105 \mathrm{~mm} \mathrm{f} / 4.5$ & $10 \mu \mathrm{s}, 10 / 15 \mathrm{kHz}$ & $4.72 \mathrm{pixel} / \mathrm{mm}$ & $307 \mathrm{~nm}(10 \mathrm{n}$ \\
Sandia & $\mathrm{OH}^{*}$ & UV & $105 \mathrm{~mm} \mathrm{f} / 4.5$ & $3 \mathrm{~ms}$ & $11.5 \mathrm{pixel} / \mathrm{mm}$ & $308 \mathrm{~nm}(10 \mathrm{n}$ \\
Sandia HS & $\mathrm{OH}^{*}$ & S20 & $105 \mathrm{~mm} \mathrm{f} / 4.5$ & $2 \mu \mathrm{s}, 20 \mathrm{kHz}$ & $5.39 \mathrm{pixel} / \mathrm{mm}$ & $308 \mathrm{~nm}(10 \mathrm{r}$ \\
\hline IFPEn & $\mathrm{OH}$ & RB Slow & $45.5 \mathrm{~mm} \mathrm{f} / 1.8$ & $50 \mathrm{~ns}$ & $10.29 \mathrm{pixel} / \mathrm{mm}$ & $315 \mathrm{~nm}(25 \mathrm{n}$ \\
TU/e & $\mathrm{OH}$ & UNIGEN II & $100 \mathrm{~mm} \mathrm{f} / 2$ & $50 \mathrm{~ns}$ & $31.95 \mathrm{pixel} / \mathrm{mm}$ & $315 \mathrm{~nm}(25 \mathrm{n}$ \\
\hline IFPEn & $\mathrm{CH}_{2} \mathrm{O}$ & RB Slow & $45.5 \mathrm{~mm} \mathrm{f} / 1.8$ & $50 \mathrm{~ns}$ & $10.29 \mathrm{pixel} / \mathrm{mm}$ & $474 \mathrm{~nm}(80 \mathrm{n}$ \\
TU/e & $\mathrm{CH}_{2} \mathrm{O}$ & UNIGEN II & $100 \mathrm{~mm} \mathrm{f} / 2$ & $10 \mathrm{~ns}$ & $13.62 \mathrm{pixel} / \mathrm{mm}$ & $425 \mathrm{~nm}(50 \mathrm{n}$ \\
Sandia & $\mathrm{CH}_{2} \mathrm{O}$ & HBf & $105 \mathrm{~mm} \mathrm{f} / 4.5$ & $250 \mathrm{~ns}$ & $5.16 \mathrm{pixel} / \mathrm{mm}$ & $418 \mathrm{~nm}(65 \mathrm{n}$ \\
\hline
\end{tabular}

downstream of the injector, the FLOL, which is one of the primary reference parameters for model validations. For this reason, the FLOL has been the subject of many previous studies where the $\mathrm{OH}^{*}$ radical has been used as a marker for the flame front $[13-16,20]$. Since the chemiluminescence of $\mathrm{OH}^{*}$ is imaged through band-pass filters, that have low yet finite transmission outside the spectral range of interest, it is important to consider the black body radiation of soot particles over the entire spectrum. Although photocathode quantum efficiency decreases at longer wavelengths and filter transmission is low, soot incandescence can be orders of magnitude more intense than $\mathrm{OH}^{*}$, and may also contribute emission near the intended 310-nm collection [31, 32]. However, at Spray A conditions the first formation of soot occurs at a finite distance downstream of the FLOL [33], and therefore soot incandescence is not interfering at the main region of interest for these experiments.

\subsection{Planar laser-induced fluorescence}

PLIF was used to detect products of both high-temperature reactions and low-temperature chemistry of Spray A and parametric variations thereupon. 
The most important details are listed in Table 2. Similar to $\mathrm{OH}^{*}$ chemiluminescence, ground state $\mathrm{OH}$ can be used as a marker originating from (but not restricted to) the flame front, with PLIF obviously providing the advantage of restricting the detection of the radical to a thin plane [12, 16-18, 34]. To probe the ground state $\mathrm{OH}$ radicals, a frequency-doubled dye laser operated on Rhodamine $6 \mathrm{G}$ was used by IFPEn and TU/e. Both dye lasers were pumped using a frequency-doubled Nd:YAG laser at $532 \mathrm{~nm}$. IFPEn induced excitation at a wavelength of $282.92 \mathrm{~nm}$, while $\mathrm{TU} / \mathrm{e}$ probed the $\mathrm{OH}$ radical at a wavelength of $283.93 \mathrm{~nm}$, corresponding to the $\mathrm{Q}_{1}(6)$ and $\mathrm{Q}_{1}(9)$ transitions, respectively. Both institutes used an off-resonance correction for the obtained results by tuning the dye laser to a wavelength of $283.10 \mathrm{~nm}$ and $283.83 \mathrm{~nm}$ for IFPEn and TU/e, respectively. IFPEn formed a laser sheet of $18 \mathrm{~mm}$ x $0.5 \mathrm{~mm}$ but conducted experiments at two axial positions to provide data over $35 \mathrm{~mm}$. The detection of OH PLIF by IFPEn was achieved using an identical experimental approach compared to $\mathrm{OH}^{*}$ but with an exposure time of $50 \mathrm{~ns}$. TU/e performed experiments with a single laser sheet of $30 \mathrm{~mm} \times 0.5 \mathrm{~mm}$. The detection of $\mathrm{OH}$ PLIF at TU/e was performed using an intensified CCD camera (Princeton Instruments, PI-MAX3) equipped with a Bernhard Halle lens (B. Halle Nachfl., $100 \mathrm{~mm}, \mathrm{f} / 2$ ) and the Semrock filter-set of IFPEn, using a gate time identical to that of IFPEn.

Fluorescence from the vibronic bands of formaldehyde has been imaged by TU/e, IFPEn and Sandia, using the third harmonic output of a Nd:YAG laser at $355 \mathrm{~nm}$ for excitation. The laser sheet sizes and energy were: $40 \mathrm{~mm} \mathrm{x}$ $0.5 \mathrm{~mm}$ at $160 \mathrm{~mJ} /$ pulse (TU/e), $45 \mathrm{~mm} \times 0.5 \mathrm{~mm}$ at $100 \mathrm{~mJ} /$ pulse (IFPEn) and $60 \mathrm{~mm} \times 0.3 \mathrm{~mm}$ at $100 \mathrm{~mJ} /$ pulse (Sandia). All three institutes used a similar intensified CCD camera (Princeton Instruments, PI-MAX3) for the detection of formaldehyde, in combination with different filters, gate timings and lenses. TU/e used a Bernhard Halle lens (B. Halle Nachfl., $100 \mathrm{~mm} \mathrm{f} / 2$ ), a 450-nm short-pass and a 400-nm long-pass filter. A gate time on the order of the laser pulse duration was used, based on the short lifetime of formaldehyde fluorescence at elevated temperature and pressure [35], and large amounts of potential spectral interference. IFPEn used a Sodern lens (CERCO $45.5 \mathrm{~mm}$ f/1.8), a band-pass filter at $474 \mathrm{~nm}(80 \mathrm{~nm}$ FWHM) and a gate time of $50 \mathrm{~ns}$. At IFPEn, the formaldehyde PLIF experiments were conducted simultaneously with OH PLIF measurements. Sandia used a Nikon lens (Nikkor 50 mm, f/1.2), a 450-nm short-pass filter and a 385-nm long-pass filter with a gate time of 250 ns. Sandia and TU/e recorded background images with their individual settings without laser illumination to correct for the bulk flame luminosity. Sandia performed an additional background correction based on laser illumination of non-reacting sprays to preclude elastic scattering and fuel PLIF. IFPEn recorded a background image with representative boundary conditions and laser illumination, but without fuel injection. Previous studies have shown that 355-nm PLIF images contain a significant contribution originating from elastic scattering (mainly from the liquid fuel), Laser-Induced Incandescence (LII) of soot and fluorescence of Poly-Aromatic Hydrocarbons (PAH) [17, 18, 24, 25, 36-38]. These studies also have shown that formaldehyde features can nevertheless be 
distinguished by considering the spatial and temporal structure, as well as relative intensities of individual contributions to the signal. The Spray A condition has already been the subject of many studies [1-5, 20-22, 24, 25, 27]. For this study, the available spatio-temporal information on many species aids in interpreting the specific contributions to PLIF images using excitation at $355 \mathrm{~nm}$, as will be discussed.

\section{Results and discussion}

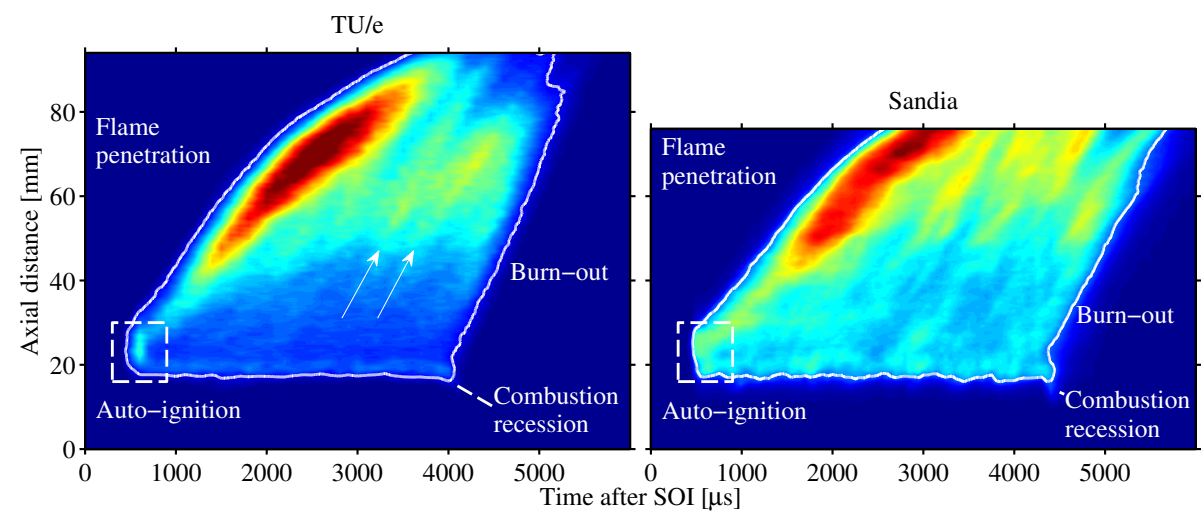

Figure 3: Radially integrated $\mathrm{OH}^{*}$ intensity obtained by $\mathrm{TU} / \mathrm{e}$ and Sandia as a function of axial distance and time, with a contour defined by the intensity at the location of the steady FLOL. Note that the $I_{x t}$ plot created from the results of Sandia is based on a single experiment. Bilinear interpolation is used to enhance image resolution. Various features have been identified in the figures to support the analysis provided in the text.

\subsection{Spray A baseline}

Given a sufficiently long injection duration and constant fuel injection rate, many processes upstream of the penetrating spray head can be considered as quasi-steady $[12,39]$. Because the constant-volume vessels used in this study permit long injection durations (as compared to most reciprocating engines), sufficient time is available to allow the development and analysis of quasi-steady behavior in the reacting fuel spray. Previous work has indicated consistency in combustion-related phenomena among ECN contributors despite small differences in vessel geometries, injector details, and boundary conditions [3-5]. Using the remaining and mostly identified deviations and resulting recommendations based on these previous comparisons has allowed for a further convergence of quasi-steady results in the Spray A baseline test case. To further explore and understand the combustion processes, a longer injection duration has been applied to study the quasi-steady flame of the reacting fuel spray. In addition to that, the transient flame structures have been studied as well, with emphasis on the early development of the reacting spray. 


\subsection{1. $\mathrm{OH}^{*}$ Chemiluminescence}

Comparisons of the $\mathrm{OH}^{*}$ images such as Figure 2, and with a standardized method to process and quantify the FLOL, have been reported in previous work [4]. The structure in these classical $\mathrm{OH}^{*}$ images can be interpreted as being composed of (narrow-band) $\mathrm{OH}^{*}$ emission and (broad-band) soot luminosity. A narrower detection bandwidth (centered around the $\mathrm{OH}^{*}$ emission), or relatively larger transmission with respect to longer wavelengths, will then lead to a stronger $\mathrm{OH}^{*}$ contribution relative to that of soot. This is consistent with an interpretation of the most upstream signal as being due to $\mathrm{OH}^{*}$ emission, while downstream, where soot forms a significant distance away from the FLOL [33], the signal is from both $\mathrm{OH}^{*}$ as well as soot or large PAH luminosity. The start and duration of camera exposure have a significant influence on the downstream structure of the imaged spray. Starting the exposure shortly after auto-ignition will broaden the structure due to inclusion of the spray head, inherently coupled to the detection of incandescence further upstream. This is an important aspect to consider for images discussed in this work, where a contour of such recordings is used to indicate the outline of $\mathrm{OH}^{*}$.

The high-speed approach to detect $\mathrm{OH}^{*}$ chemiluminescence of the Spray A test case by $\mathrm{TU} / \mathrm{e}$ and Sandia allows a time-dependent analysis. The intensity $I(x, y, t)$ can be integrated along the radial direction of the spray $(y)$ according to,

$$
I_{x t}=\int_{-\infty}^{\infty} I(x, y, t) \mathrm{d} y,
$$

retaining information on the intensity $I_{x t}$ as a function of axial distance $x$ and time $t$. Plots generated using this integration will therefore be denoted as $I_{x t^{-}}$ plots. Each pixel column in such a plot is a false-color representation of the total intensity along the spray axis at a given moment in time, examples of which are shown in Figure 3. Note that, unlike several subsequent results, these $I_{x t}$-plots are based on the original line-of-sight data. In order to illustrate the quasi-steadiness in the upstream region where $\mathrm{OH}^{*}$ is detected, iso-intensity lines have been plotted that coincide with the lift-off lengths deduced from the time-averaged results of TU/e and Sandia, respectively. Starting from the first detection of $\mathrm{OH}^{*}$ around $400 \mu$ s after the SOI, the image of TU/e in particular shows a bright region of chemiluminescence in which an amount of premixed fuel is burnt with the initial high-temperature reactions. Soot is expected downstream $(>30 \mathrm{~mm})$ and at least shortly after auto-ignition $(>800 \mu \mathrm{s})[6]$. Shortly afterwards the lift-off region stabilizes, whereas the head of the spray continues to penetrate further into the combustion vessel. This flame penetration can be observed in the upper left region of the images. A decrease in velocity downstream of the injector due to the radial expansion and momentum exchange encountered by the jet is observed clearly in both images. After the end of injection, the luminous combustion is seen to split into two parts, one short tail traveling upstream ("combustion recession") and a second tail, corresponding 
to burn out of the jet, traveling downstream. The progression of the luminous zone towards the injector is similar to the observations and analyses of previous studies, and can be interpreted as an ignition event [20, 25, 40,41].

Musculus and Kattke used experimental observations to develop a model which features a so-called "entrainment wave" traveling downstream through the jet at twice the initial jet penetration velocity after the EOI. This entrainment wave has been shown to increase the entrainment after EOI by a factor three [42]. The relatively high, but stable, velocity at which the remainder of the flame travels after the end of injection (labeled "Burn-out" in Figure 3), illustrates that the sudden stop of fuel supply results in an increased velocity and enhanced mixing compared to the penetrating head. The model developed by Musculus and Kattke shows that the entrainment wave produces linear propagation of the averaged axial velocity and equivalence ratio after the EOI. With similar linearity demonstrated in the experiment, this indicates that the observed burnout is governed by the local equivalence ratio.

Parallel streaks of relatively high intensity between 40 and $80 \mathrm{~mm}$ downstream of the injector in the central part of both $I_{x t}$-plots are identified by white arrows in the TU/e plot. Similar streaks are visible in the Sandia result as well, and indicate reproducible high-intensity features traveling downstream during the experiments. The velocities of the streaks are in between the initial flame penetration and that of the burn-out phase. In original image sequences (available at [30]), these features appear to originate from growing soot clouds that entrain fresh charge which are subsequently transported downstream along the periphery of the spray. This is consistent with observations of increased ambient entrainment in single-phase jets with an imposed velocity reduction [43], and therefore suggestive of minor entrainment waves caused by repeatable fluctuations in the rate of injection.

The higher intensity regions in Figure 3 starting around $1 \mathrm{~ms}$ after SOI at a distance of about $35 \mathrm{~mm}$ downstream of the injector, correspond to observations made in soot studies at Spray A conditions [6, 21]. This observation further substantiates the hypothesis that the regions downstream of $35 \mathrm{~mm}$ in $\mathrm{OH}^{*}$ recordings are heavily polluted by soot incandescence, which will be covered in more detail when the relations between detected species are discussed.

\subsection{2. $O H P L I F$}

The ensemble-averaged results of OH PLIF experiments by TU/e and IFPEn are presented in Figure 4. The injection duration in TU/e PLIF experiments was extended from 3.8 to $5 \mathrm{~ms}$, with respect to the high-speed $\mathrm{OH}^{*}$ chemiluminescence recordings. Both institutes performed single-shot OH PLIF experiments to visualize the initial high-temperature reactions after auto-ignition, and the quasi-steady structure in a planar cross section. The time after SOI is indicated in all images of Figure 4, and the corresponding flame penetration from Figure 3 is shown by a dotted line. Note that in this figure the IFPEn images are a collage of two, individually normalized and ensemble-averaged images, with different laser light sheet locations (glued at $23 \mathrm{~mm}$ downstream of the injector). The reduced signal at this location $(23 \mathrm{~mm})$ indicates lack of laser energy at the 


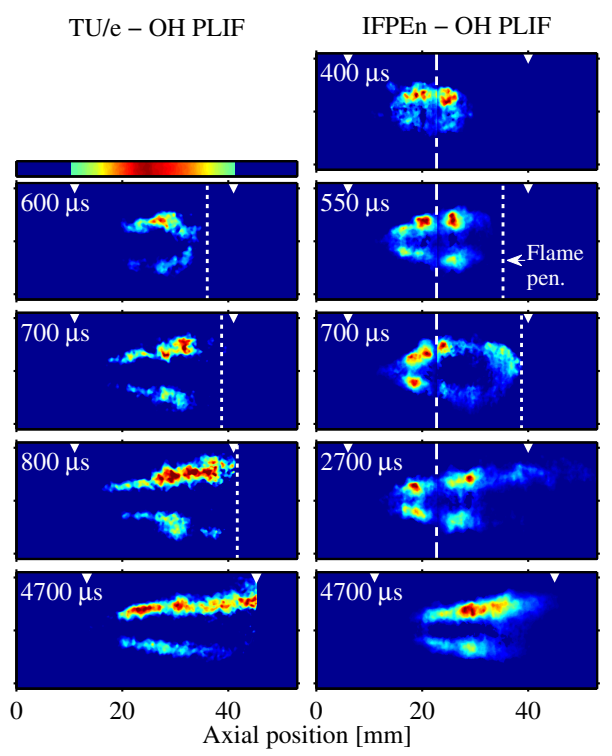

Figure 4: Development of OH PLIF structures obtained by TU/e and IFPEn at Spray A conditions. The TU/e data have been normalized for the laser intensity distribution indicated by the color bar in the top, left column. Note that an exact match in timing only occurs at 700 and $4700 \mu$ s after SOI, and that the injection duration was $5 \mathrm{~ms}$ for both TU/e and IFPEn. The white dashed lines in the top recordings of IFPEn indicate the location where images were combined. White dotted lines indicate TU/e flame penetration according to the contours of Figure 3.

edge of the laser sheet. As compared to the chemiluminescence experiments, the signal obtained from OH PLIF is confined to a smaller region of the flame and depends on the local laser excitation energy. White arrowheads in the images indicate the approximate limits of the laser sheet, which passes from top to bottom in these experiments. The lower $\mathrm{OH}$ branch is in general less bright than the upper one, which is attributed to excitation laser light being attenuated by the central regions of the spray $[17,44]$. The laser sheet intensity distribution of TU/e experiments has been retrieved by recording the elastic scattering of still gas in the high-pressure facility (accumulation of 1000 laser shots). Using this distribution to normalize the detected fluorescence improves the represented signal for experiments near the lift-off location. The sheet intensity distribution is included in the top of the figure for the $600 \mu \mathrm{s}$ case, where the cut-offs at 11 and $41 \mathrm{~mm}$ from the injector orifice (coincident with the white arrows) indicate the field-of-view of the camera for TU/e experiments. However, using the normalization enhances artifacts in regions with low laser energy. Since the main interest for OH PLIF in those images is the upstream part of the spray flame, both IFPEn and TU/e attempted to illuminate this whole region with sufficient excitation energy. Due to this focus, the above-mentioned artifacts occur further downstream and, therefore, at late timings in particular. Note 
that the PLIF normalization procedure has only been applied to the OH PLIF results obtained by $\mathrm{TU} / \mathrm{e}$, since these were the only experiments for which the laser sheet intensity distribution was available.

The first OH PLIF image by IFPEn in Figure 4 corresponds to $400 \mu \mathrm{s}$ after SOI, shortly after the ignition delay $[4,26]$. At this timing, images are relatively structureless. The typical spray flame structure, with an envelope of OH surrounding a (more fuel-rich) core, only shows up later after SOI (550 and $600 \mu$ s for IFPEn and TU/e, respectively). The less regular distribution of $\mathrm{OH}$ fluorescence intensity in the image at $400 \mu \mathrm{s}$, supports the contention that during the initial high-temperature combustion, partially premixed fuel is consumed in local pockets. This likely resulted in the relatively high $\mathrm{OH}^{*}$ chemiluminescence signal observed in the lower left of the $I_{x t}$ plots (Figure 3) as well. At $700 \mu \mathrm{s}$, less coherent images are observed compared to the quasi-steady case. Overall, $\mathrm{OH}$ is visible at the head of the penetrating jet briefly during ignition and up to $700 \mu$ s with slight variations between individual institutes, but not after reaction progresses and the jet head moves downstream of the laser sheet. The images at 800 and $2700 \mu$ s in Figure 4 correspond to timings which can already be considered as quasi-steady.

The similarity of the quasi-steady results in the bottom of Figure 4 is expected, given that TU/e and IFPEn both used the same filter pack and an identical 50-ns gate time triggered $4.7 \mathrm{~ms}$ after SOI. The resulting images clearly illustrate how $\mathrm{OH}$ is found in the presumed high-temperature region in the periphery of the spray where $\mathrm{OH}^{*}$ is detected, surrounding a more fuel-rich central volume with lower temperatures $[33,45,46]$. Comparing both OH PLIF images we observe a steep fluorescence intensity increase at similar locations downstream of the nozzle, which is more pronounced in the TU/e results. It cannot be ruled out that the slight downstream shift in the IFPEn results on this position, as compared to previous timings, is an artifact caused by laser intensity fluctuations.

\subsubsection{Formaldehyde PLIF}

For the imaging of formaldehyde PLIF, more substantial differences in detection methodology among the three institutions exist, as discussed in subsection 3.2. Due to these differences, extra care is required when comparing the individual images. The evolution of the formaldehyde signal in time is presented in Figure 5, where the time after SOI is indicated in all images. The white arrowheads in the top of each image indicate approximate limits of the laser sheet. An exact match in timing is shown at $700 \mu$ s between IFPEn and Sandia, and at $4700 \mu$ s by IFPEn and TU/e. The other cases are sufficiently close in timing to warrant comparison.

The first images shown in Figure 5, obtained by Sandia and IFPEn, show the early structure of formaldehyde, still without obvious contributions of PAH fluorescence. Though not reproduced here, Skeen et al. [25] observed formaldehyde PLIF as early as $190 \mu$ s after SOI for the Spray A condition. The region along the jet axis in which the fluorescence signal is interpreted as being due 


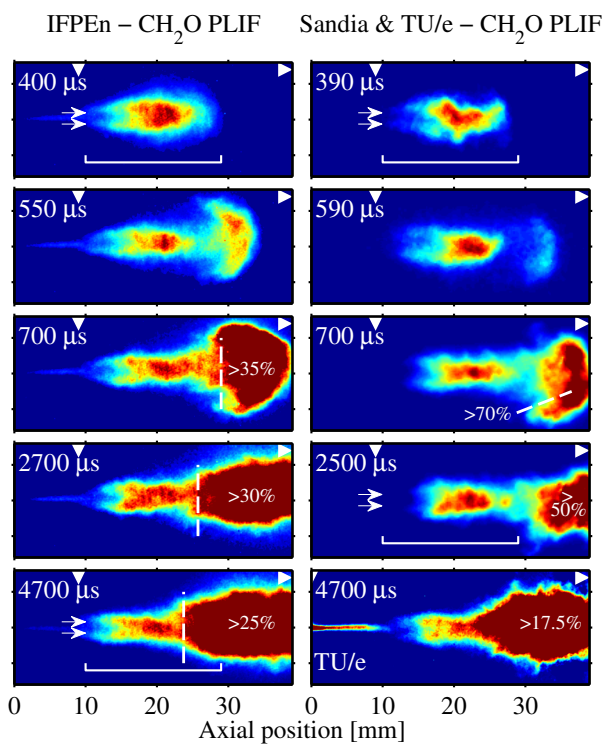

Figure 5: False-color PLIF images showing ensemble-averaged formaldehyde structures at different timings, obtained by IFPEn, Sandia and TU/e at Spray A conditions. Markings are provided to illustrate laser sheet extent, and time-dependent structural behavior (see text for details). Displayed dynamic ranges have been adjusted to emphasize the $\mathrm{CH}_{2} \mathrm{O}$ structure. Regions which become saturated due to the adjusted color palette are indicated by percentages. Images from Sandia at $390 \mu \mathrm{s}$ and $590 \mu \mathrm{s}$ are single-shot recordings, the image at 390 has been reported in a previous study [24].

to formaldehyde is indicated by a white bracket in the first image of both sequences. As observed in previous work [24, 36], distinct fluorescence lobes of formaldehyde can be identified above and below the spray axis downstream of the first axial position where formaldehyde is detected (indicated by white arrows). When moving radially inwards from these lobes the local equivalence ratio increases, and mixture temperature most likely decreases, which was studied by Idicheria and Pickett with various different boundary conditions [36]. This change in mixture temperature and local equivalence ratio presumably gives rise to the reduced signal strength of formaldehyde near the spray axis at this location due to local regions which have not gone through first-stage ignition. In the work by Idicheria and Pickett, this was substantiated by adiabatic mixing calculations of non-reacting jets at various ambient temperatures, and mixture temperature measurements from Rayleigh scattering. Note that the intensity upstream of the white arrows in the recordings by IFPEn, is caused by elastic scattering of light off the liquid fuel, which is not suppressed by the optical filters. The formaldehyde structure reaches up until the approximate head of the jet around $400 \mu \mathrm{s}$ after SOI. Although the formaldehyde signal in the central core of the jet within the upstream lobe regions is less intense, we point out that the most intense signal is in fact observed slightly downstream 
near the center of the jet head where Rayleigh scattering mixture measurements have demonstrated equivalence ratios exceeding $\phi=4$. Dahms et al. [47] introduced the term "turbulent cool flame wave" to describe the rapid progression of first-stage ignition from the leaner hotter regions into the cooler richer regions. Thus, first-stage ignition appears to initiate in the radial upstream lobes whereafter heat and reactive intermediates are transported downstream by convection and into the jet core by rapid diffusion due to steep temperature and species gradients. The rapid transport of heat and reactive intermediates into the core of the jet slightly downstream of these lobes accelerates first-stage ignition in fuel-rich regions that would normally be characterized by much longer ignition delay times. In the images at 550 and $590 \mu$ s after SOI, the same characteristic lobes are still observed upstream, which were previously identified with arrows. Downstream of these lobes, the radial extent of the formaldehyde structure increases and becomes more homogeneous over the entire spray when approaching the location of the FLOL (around $17 \mathrm{~mm}$ from the injector orifice for Spray A conditions). Downstream of the FLOL (between 18 and $28 \mathrm{~mm}$ from the injector orifice), formaldehyde is consumed when approaching the periphery of the spray by the high-temperature diffusion flame. Inside the contours of the diffusion flame formaldehyde mixes and interacts with high-temperature products, confining the structure over the radial component until it becomes indiscernible with respect to the presence of PAH. Further downstream of this location, PAH fluorescence can be recognized by the radial expansion and increased intensity as identified at Spray A conditions by Skeen et al. [24].

Since the signal further downstream in subsequent images is dominated by increasing amounts of PAH fluorescence, the displayed dynamic ranges are adjusted. By adjusting the displayed intensity range, regions with $\mathrm{PAH}$ appear saturated, indicated by percentages to illustrate the quantitative contribution of the downstream region. For instance, in case of the image by IFPEn at 700 $\mu$ s after SOI, this means that only up until $35 \%$ of the maximum intensity is displayed. This contribution of PAH appears to persist until the end of the spray or the end of the laser sheet for all images.

In the final image of IFPEn $(4700 \mu \mathrm{s})$ and Sandia $(2500 \mu \mathrm{s})$, the white brackets are shown at identical locations as in the first recording to illustrate small spatial changes of the structures. Similar to a stabilized structure of $\mathrm{OH}$ and $\mathrm{OH}^{*}$ at the lift-off region, the entire appearance of formaldehyde does not vary significantly during the injection event. Considering the onset of PAH fluorescence, there appears to be an upstream shift over time, which is presumably caused by increasing background luminosity as the flame matures. This apparent shift is especially visible from the images of 700 to $4700 \mu$ s obtained by IFPEn (pointed out by a white dashed line which coincides with the most upstream location where saturation occurs when normalizing to $\mathrm{CH}_{2} \mathrm{O}$ intensity).

When comparing the final images of all three institutes, the Sandia result shows a relatively high intensity of formaldehyde with a more pronounced separation to the PAH and soot region at a larger distance from the injector orifice. Based on the higher laser intensity and red-shifted filters used by TU/e and IFPEn, it is likely that Sandia obtained less PAH PLIF and LII signal, increasing 
the relative signal strength originating from formaldehyde fluorescence. Possible non-linear effects might affect the relative fluorescence yield, but given the similar fluences in experiments by different institutes, it seems unlikely that they can explain the differences in Figure 5. In addition to this, the aforementioned apparent shift of PAH fluorescence explains a significant part of the differences in the quasi-steady results between all three institutes. Later in this paper, the sensitivity of PAH and formaldehyde to changes in ambient temperature will be discussed in more detail.

\subsubsection{Relations between detected species}
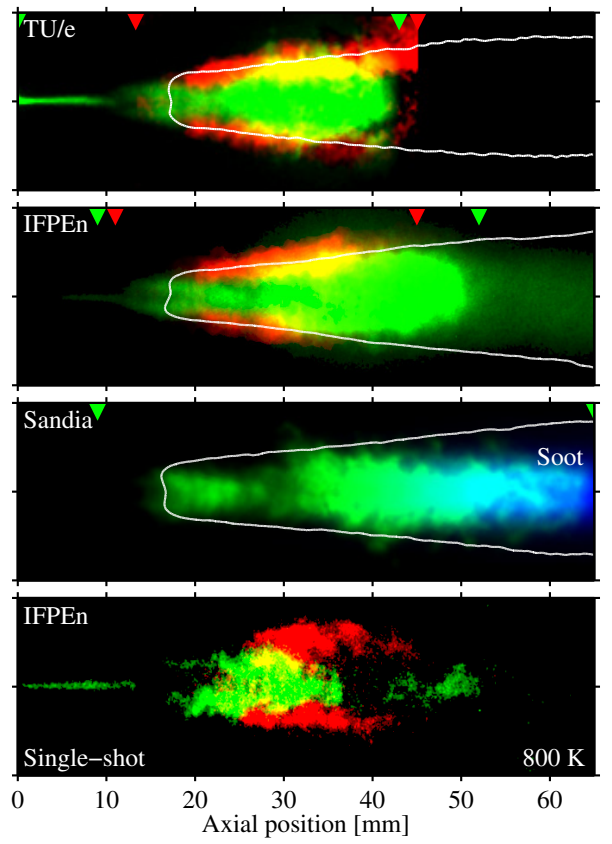

Figure 6: Combination of results showing the spatial relation between $\mathrm{OH}$, formaldehyde, and previously obtained soot volume fraction available from the ECN database $[1,48]$. The results of individual experiments are color-coded, using green for the $\mathrm{CH}_{2} \mathrm{O}$ and PAH PLIF experiments, red for OH PLIF and blue for soot volume fraction. The white lines show the contour of $\mathrm{OH}^{*}$ and incandescence based on the intensity at the lift-off length. The bottom panel shows simultaneously acquired single-shot images of $\mathrm{OH}$ and formaldehyde PLIF by IFPEn at an ambient temperature of $800 \mathrm{~K}$. The $\mathrm{CH}_{2} \mathrm{O}$ and PAH results in the second panel are not corrected for the background luminosity and show some weak diffuse signal outside the laser sheet and jet boundaries.

The good reproducibility of Spray A conditions between participating institutes has allowed a direct comparison of results obtained in different test facilities. In a similar fashion, this reproducibility and the quasi-steady behavior of the spray flame allows a comparison between detected species relevant for the flame structures based on ensemble-averaged experiments. In the upper 
three panels of Figure 6, the combined results obtained using different diagnostic techniques at quasi-steady conditions are presented for each institute, using color-coding for the individual experiments and corresponding laser sheet locations. In the bottom panel, a single-shot recording of simultaneous $\mathrm{OH}$ and $\mathrm{CH}_{2} \mathrm{O}$ at a relatively low ambient temperature is presented. The white lines in the upper images are iso-intensity lines of $\mathrm{OH}^{*}$ (including the contribution of incandescent soot), indicating the spatial structure of these recordings; these contours are based on the intensity level at the lift-off length. The green color represents formaldehyde and PAH PLIF excited at $355 \mathrm{~nm}$, while OH PLIF results are represented in red. The blue color in the image of Sandia indicates the soot volume fraction for Spray A obtained in a previous study [49]. An overlap in $\mathrm{OH}$ and formaldehyde and PAH PLIF results in a yellow color.

Formaldehyde appears at a discernible distance upstream of OH PLIF for both IFPEn and TU/e, and precedes the FLOL determined by $\mathrm{OH}^{*}$ recordings for all institutes. There is no significant spatial overlap in formaldehyde and $\mathrm{OH}$ PLIF signal (noting that the $\mathrm{CH}_{2} \mathrm{O}$ is in the upstream region), an observation that has been reported in simultaneous detection measurements in other studies as well $[17,18,50]$. In combination with both the white $\mathrm{OH}^{*}$ contour and the red OH PLIF signal, consumption of formaldehyde near the high-temperature reaction zone is evident. Regarding the fluorescence originating from $\mathrm{PAH}$, we see that it remains relatively confined to the spray center. In the Sandia measurements, the quasi-steady signal from soot volume fraction measurements starts at a distance of approximately $40 \mathrm{~mm}$ downstream, where it overlaps with the $\mathrm{CH}_{2} \mathrm{O}$ and $\mathrm{PAH}$ signal (cyan color); further downstream the results of the two diagnostic techniques seamlessly supplement each other. The appearance of increasing soot volume fraction coincides with the increasing intensity observed in the $I_{x t}$-plots, supporting the interpretation that the downstream luminosity is in fact due to soot rather than $\mathrm{OH}^{*}$. Soot precursors tend to grow over time and axial distance, preceding oxidation in the hot flame front. As the signal from soot volume fraction measurements starts at a larger distance from the injector orifice compared to PAH fluorescence, it is expected that smaller soot-precursor PAHs have been excited using PLIF [51].

To address effects by averaging experiments, a combined image of simultaneously detected single-shot recordings at an ambient temperature of $800 \mathrm{~K}$ by IFPEn is shown in the lower panel of Figure 6. By adjusting the intensity range for both $\mathrm{OH}$ and $\mathrm{CH}_{2} \mathrm{O}$ PLIF to a range between 0 and $25 \%$, low intensity regions have been amplified. Here again, $\mathrm{OH}$ surrounds the formaldehyde structure, and minimum overlap between signals can be observed (yellow color). The $\mathrm{OH}$ branches similarly reduce the radial extent of formaldehyde, indicating consumption in the high-temperature reactions.

Considering the relation between $\mathrm{OH}$ and $\mathrm{OH}^{*}, \mathrm{OH}$ PLIF signal appears at a distance which is distinctly further downstream than the onset of the $\mathrm{OH}^{*}$ signal, and reported FLOL values [1]). This is in line with previous studies in internal combustion engines with similar thermodynamic conditions [16, 52]. Downstream of the FLOL, it seems that the contour of $\mathrm{OH}^{*}$ in Figure 6 intersects the OH PLIF signal exactly at the maximum. As the contour is determined by 
the relatively low intensity at the FLOL region, this may be an indication that $\mathrm{OH}$ is found at a larger radial distance from the spray axis, where $\mathrm{OH}^{*}$ no longer persists. But in order to directly compare the line-of-sight $\mathrm{OH}^{*}$ recordings and the planar OH PLIF images, an inverse Abel transformation is used to approximate the $\mathrm{OH}^{*}$ along a plane. The images obtained by the line-of-sight recordings of $\mathrm{OH}^{*}$ chemiluminescence are considered to be axisymmetric about the central spray axis of the injector. Under this assumption, and that of no $\mathrm{OH}^{*}$ absorption, the inverse Abel transform can be used to reconstruct a $2 \mathrm{D}$ radial cross section from a line-of-sight image, according to

$$
I_{2 D}=-\frac{1}{\pi} \int_{r}^{\infty} \frac{d I_{O H^{*}}}{d y} \frac{d y}{\sqrt{y^{2}-r^{2}}} .
$$

Starting from the central axis of the spray, this inversion is performed over 180 degrees, separately for both the upper and the lower part of the spray. Figure 7 presents the quasi-steady, inverse-Abel-transformed $\mathrm{OH}^{*}$ images of TU/e and IFPEn, combined with a contour of OH PLIF at an intensity threshold of $15 \%$, with respect to the maximum signal. We observe the onset of the $\mathrm{OH}$ distribution to be shifted downstream relative to that of $\mathrm{OH}^{*}$. At first sight this might appear contradictory, since, after all, all $\mathrm{OH}^{*}$ becomes $\mathrm{OH}$ after photon emission. In an internal combustion engine with simultaneous detection of $\mathrm{OH}$ PLIF and $\mathrm{OH}^{*}$, an offset between $\mathrm{OH}^{*}$ emission and $\mathrm{OH}$ PLIF along a plane was considered to be caused by asymmetries in the flame shape, including $\mathrm{OH}^{*}$ not in the plane of the laser sheet [16]. More recently, these observations were studied in more detail by comparing optical engine results to a lifted methane diffusion flame and numerical simulations [52], where it was additionally shown how the collection angle in combination with a thin laser sheet further biases the increased LOL based on OH PLIF. The collection angle, however, is of no concern for OH PLIF in a combustion vessel. Concentrations of $\mathrm{OH}$ and $\mathrm{OH}^{*}$ may differ significantly in any spray flame. However, while all $\mathrm{OH}^{*}$ either quenches or contributes to the chemiluminescence signal, only a few rotational states of $\mathrm{OH}$ contribute to the PLIF signal, which implies that detection sensitivity is not the same for both cases. The OH-distribution in Figure 7 is also seen to be broader than that of $\mathrm{OH}^{*}$ in the radially outward direction, similar to the lifted methane flame. This is a consequence of the inherently larger lifetime of $\mathrm{OH}$, and can be well visualized when reducing the influence of laser intensity by considering the normalized intensity as function of the radial position in a finite region. The lower panels of figure Figure 7 show the normalized intensity of $\mathrm{OH}$ and $\mathrm{OH}^{*}$ axially integrated over the equally colored boxes in the upper images at locations 1 and 2. In all cases, the $\mathrm{OH}$ distribution is seen to be shifted radially outwards relative to that of $\mathrm{OH}^{*}$, despite the sensitivity of the radial location of OH PLIF to the alignment between the laser sheet and the spray axis. Note that a threshold of $15 \%$ is not always reached in box 1 .

To put the observed relations between the species detected in this study into perspective, representative non-premixed igniting counterflow flame sim- 

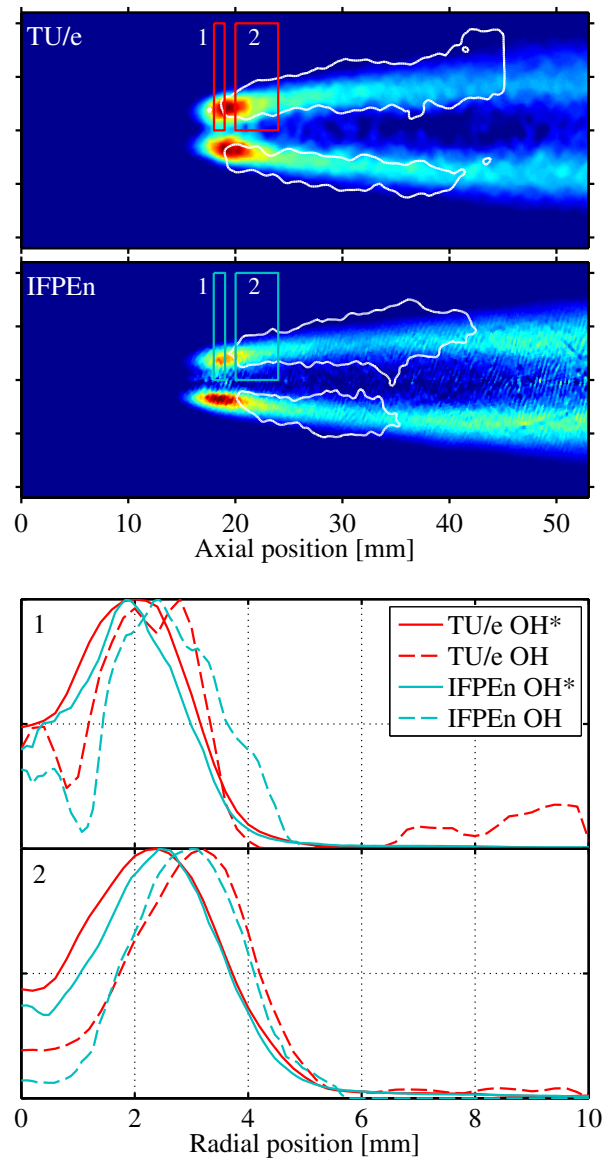

Figure 7: Combination of inverse-Abel-transformed $\mathrm{OH}^{*}$ luminescence distribution (false colors) and the contour (white) of OH PLIF at $15 \%$ of the maximum intensity, as recorded by TU/e and IFPEn. The laser sheet correction was not applied to the contours in this comparison. The bottom panels show the average intensity as a function of radial distance in the corresponding colored boxes at location 1 and 2 .

ulations were performed using the chemical kinetics mechanism proposed by Narayanaswamy et al. [53], augmented with a small set which describes $\mathrm{OH}^{*}$ chemistry, which is compiled from [54-56]. The results of such simulations are often tabulated, serving as a lookup table in a Flamelet Generated Manifold (FGM) approach [11, 57], or a Representative Flamelet in RIF approaches $[8,58]$. It should be kept in mind, however, that these models are not yet validated for the present condition. The counterflow simulations were initiated with an adiabatic mixing assumption and a strain rate of $100 \mathrm{~s}^{-1}$ at an ambient oxygen concentration of $15 \%$, an ambient temperature of $900 \mathrm{~K}$, and a fuel temperature of $363 \mathrm{~K}$ (n-dodecane). Figure 8 shows the solution of the igniting flame as a function of time and mixture fraction. A fuel pocket will move 


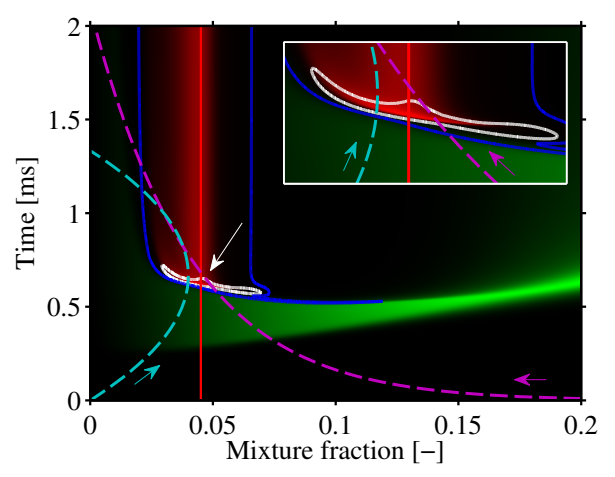

Figure 8: Igniting counterflow simulation results, showing concentrations of $\mathrm{OH}$ (in red) and $\mathrm{CH}_{2} \mathrm{O}$ (in green) at an ambient temperature of $900 \mathrm{~K}$. The stoichiometric mixture fraction is indicated by a red line. The white and blue iso-contour line represent a $1 \%$ concentration of $\mathrm{OH}^{*}$ and $\mathrm{OH}$, respectively. The dashed lines show two possible gas pocket trajectories, referred to in the text. The insert represents a zoomed view of the region where ignition occurs.

over this surface while it mixes and ignites. The normalized concentrations of $\mathrm{OH}$ and $\mathrm{CH}_{2} \mathrm{O}$ for these conditions are shown in red and green, respectively, similar to the color scheme of Figure 6 . The red line indicates the stoichiometric mixture fraction and the white iso-intensity line indicates an area with a concentration above a threshold of $1 \% \mathrm{OH}^{*}$, with respect to the maximum in the domain. Using the same threshold for $\mathrm{OH}$ results in the blue iso-intensity line, illustrating $\mathrm{OH}$ in equilibrium and the increased range of mixture fractions where the radical is detected after ignition.

In order to guide the reader and illustrate the applicability of Figure 8 to spray flame simulations, two typical gas pocket trajectories are provided. The dashed purple line shows an example of a gas pocket originating from the injector orifice, burning to completion and ending up near a global equivalence ratio at $2 \mathrm{~ms}$. The dashed cyan line shows an example of a gas pocket outside the spray which is entrained into the spray. The entrainment causes an increase in mixture fraction, after which the pocket ignites, is rejected out of the spray, and burns to completion.

Absolute values from these simulations predict $\mathrm{OH}^{*}$ concentrations up to seven orders of magnitude below those of $\mathrm{OH}$, similar to values reported by $\mathrm{Li}$ et al. [52]. Based on the applied reaction mechanism, the highest concentration of $\mathrm{OH}^{*}$ is predicted during ignition on the fuel-rich side of the stoichiometric mixture fraction, indicated by the white arrow and magnified in the insert. According to the kinetic mechanism, concentrations of $\mathrm{OH}^{*}$ are proportional to the rate of production of photons. $\mathrm{OH}$ concentrations show a maximum during ignition as well, but much less pronounced and shifted to the lean side of the flame. Furthermore, calculations show that the $\mathrm{OH}^{*}$ concentration peaks at a lower temperature compared to $\mathrm{OH}$ ( $1960 \mathrm{~K}$ versus $2100 \mathrm{~K}$, respectively). After ignition, $\mathrm{OH}^{*}$ is quickly depleted, while $\mathrm{OH}$ concentrations remain finite as the 
flame stabilizes, e.g. by thermal dissociation of $\mathrm{H}_{2} \mathrm{O}$. This corresponds with the high intensity lobes of $\mathrm{OH}^{*}$ observed in the FLOL region versus a more constant signal level of OH PLIF over the axial distance.

A number of general observations and postulates regarding the differences between $\mathrm{OH}$ and $\mathrm{OH}^{*}$ have been established in the scope of this study.

- In addition to asymmetries in the lifted flame, observed signal strength of $\mathrm{OH}$ is closer to the detection limit when compared to $\mathrm{OH}^{*}$. Consequently regions with low $\mathrm{OH}$ density remain undetected in the PLIF experiments. In fact, the observations are at least qualitatively in agreement with what would be expected if the high-temperature flame front characterized by $\mathrm{OH}^{*}$ was initially the only source of $\mathrm{OH}$.

- $\mathrm{OH}^{*}$ concentration is high at ignition and then quickly drops (by a factor of 100-1000). Peak concentrations at relatively lower temperature and higher mixture fractions compared to $\mathrm{OH}$ can lead to a relatively shorter $\mathrm{OH}^{*}$ derived FLOL. OH is found also at the high temperature regions when the counterflow flame matures towards its steady state. This explains the high intensity $\mathrm{OH}^{*}$ lobes found at the foot of the spray flame which correlates with the general conception that these flames are ignition-stabilized [59].

\subsection{Parametric variations of Spray A}

Having established a well-characterized primary reference condition allows an efficient study of individual parameters in the constant-volume facilities of contributing institutes. The effect of relevant, engine-related parameters has been studied, as indicated in Table 1. We present qualitative effects of variation in injection pressure, ambient oxygen concentration and ambient temperature on the flame structures, based upon $\mathrm{OH}^{*}$ chemiluminescence, OH PLIF, and 355-nm-excited PLIF.

\subsubsection{High-temperature reaction zones}

The effect of injection pressure, ambient oxygen concentration and ambient temperature on the quasi-steady result of the high-temperature reaction zones is shown in Figure 9. Inverse Abel transformed $\mathrm{OH}^{*}$ chemiluminescence and a contour of OH PLIF are presented similar to Figure 7. The result of the Spray A baseline is included for each variation as well, for ease of comparison. Manually placed red arrowheads at the periphery of the FLOL region of the spray indicate where the local maximum $\mathrm{OH}^{*}$ intensity is observed. These arrowheads are reproduced in summary panels for TU/e and IFPEn, respectively. Afterwards, white lines have been fitted through these locations, which are used to create the outline of a triangle to emphasize similarities in all results displayed in this figure. It turns out that all these locations are distributed over the surface of identical cones, originating in the nozzle orifice with a cone angle of approximately $17.7^{\circ}$. Spreading angles from Schlieren images, available from previous ECN studies [4, 60, 61], are generally much larger. In the case of reacting jets, the heat-released by combustion forces high-temperature combustion 

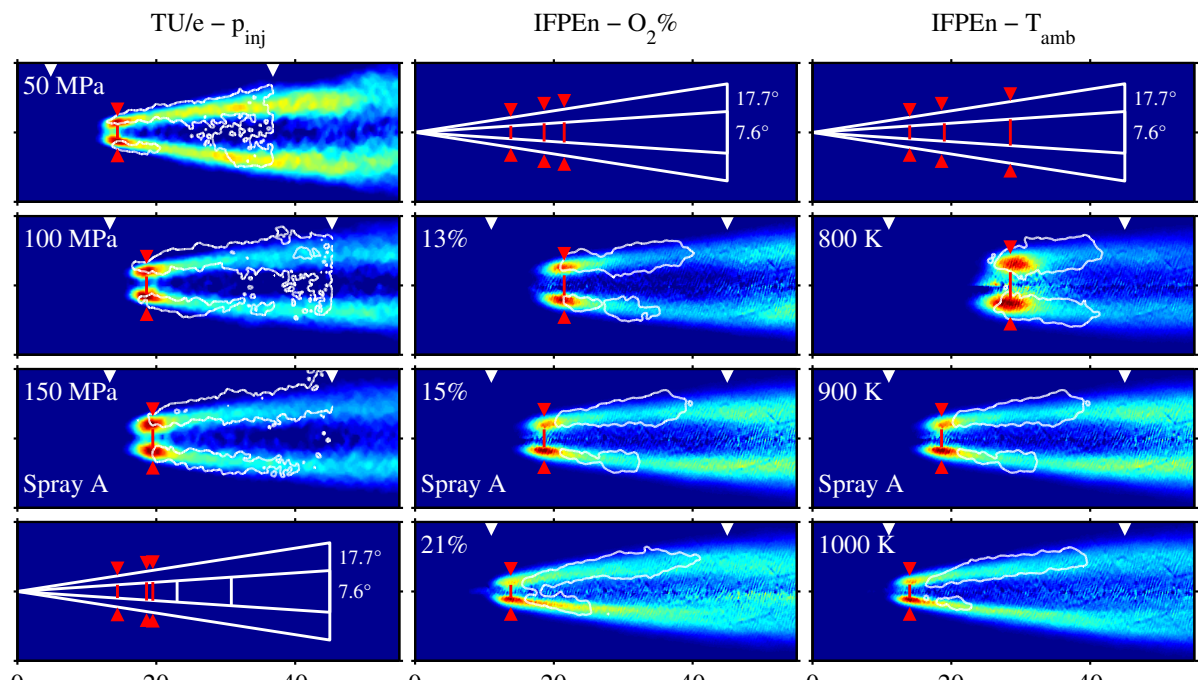

0

20

40

Axial position $[\mathrm{mm}]$

20

40

Figure 9: The effect of injection pressure, ambient oxygen concentration and ambient temperature on the results of $\mathrm{OH}^{*}$ and $\mathrm{OH}$ studied by TU/e and IFPEn. $\mathrm{OH}^{*}$ is shown in a false-color scale after an inverse Abel transformation, and all panels are individually scaled to their maximum intensity. A contour from OH PLIF recordings is shown similar to Figure 7. Extent of excitation laser light sheet is indicated by white arrowheads. See text for additional details.

products to expand in both radial and axial direction, further increasing the detected spreading angle [62]. Although cone angle values reported here are primarily intended to substantiate the discussion, the difference with spreading angles from literature can be explained by considering that the spray periphery captured in high-sensitivity Schlieren images corresponds to near-zero mixture fraction values, found radially outward of the near stoichiometric region in which chemiluminescence is detected (cf. Figure 8). The outer spray cones are subsequently supplemented with inner triangle outlines to illustrate the inner region without high-temperature combustion. The inner triangle outline is manually constructed such that it encloses the OH PLIF branches similarly in all images, resulting in a cone angle of $7.6^{\circ}$. A red line is added within this inner triangle at the location of the arrowheads obtained from the maximum $\mathrm{OH}^{*}$ intensity, and the laser sheet extent is indicated by white arrow heads in the top of each image. As with the results from figure Figure 4, the laser sheets enters the combustion vessel from above. Therefore, the lower lobes always receive less photons than the upper ones. However, the obtained results in Figure 9 allow for a qualitative analysis of $\mathrm{OH}$ and $\mathrm{OH}^{*}$ distributions, and phenomena influencing relative $\mathrm{OH}^{*}$ chemiluminescence signal intensities.

Looking at the influence of the injection pressure, there is only a small difference in FLOL and flame structure between the 100 and $150 \mathrm{MPa}$ cases (33\% reduction), compared to the case of $50 \mathrm{MPa}$ ( $50 \%$ reduction), which shows a sig- 
nificant decrease in FLOL, and radial extent of the lift-off region. Furthermore, it is observed that the intensity of the FLOL region, relative to that of the soot cloud further downstream, increases with increasing injection pressure. Qualitatively, this trend can be explained by the higher injection pressures resulting in a higher speed jet, inducing stronger turbulence and increasing air entrainment. The combustion at higher injection pressure is therefore expected to feature a stronger premixed flame at the FLOL and less soot formation later on. The $\mathrm{OH}$ contours show a generally similar trend. As indicated by the white triangle outlines, moving closer to the injector the spray flame must converge radially. On the inside, the radial extent is controlled by limited availability of oxygen and reduced temperatures in the vicinity of the liquid length. The outside is ultimately limited by the maximum radial extent of the spray as detected in Schlieren measurements due to the longer lifetime and additional source terms such as dissociation of $\mathrm{H}_{2} \mathrm{O}$, as discussed previously. A decreased thickness of the $\mathrm{OH}$ branch in radial direction is observed as well for lower injection pressures, which might be related either to the radial confinement of the spray while moving upstream, or lower spray velocities with reduced turbulence at low injection pressure. Compared to the Spray A baseline, the presence of contours near the spray axis increases for the downstream region of the flame structure with decreasing injection pressure. At the same time, the $\mathrm{OH}$ branch below the spray axis becomes significantly shorter. Based on the decreased amount of $\mathrm{OH}^{*}$ with respect to incandescent soot for these parameter variations, it is expected that a similar polluting effect is taking place for $\mathrm{OH}[14,39]$. This implies that the artifacts within the flame structure originate from detection of fluctuations in incandescence intensity which have not completely been removed by the background subtraction.

Changing the ambient conditions results in a more significant change in flame structure and FLOL. The decrease of ambient oxygen concentration down to $13 \%$ increases the FLOL and radial extent of the high-temperature products, all expected because of the reduced stoichiometric mixture fraction. The effect of changes in ambient temperature shows definite similarities with the effect of changes in ambient oxygen concentration. However, compared to a decreased ambient oxygen concentration of $13 \%$, a decrease of ambient temperature down to $800 \mathrm{~K}$ reduces the total amount of soot incandescence significantly, and now the lobes in the FLOL region appear as high-intensity regions with a significantly increased area. In spite of the artifacts induced by the inverse Abel transformation, chemiluminescence is certainly detected closer to the spray axis. More importantly, the flame downstream of this large FLOL appears not to follow the imposed divergence of the jet spreading angle. Although not shown here, due to the focus on the FLOL region, $\mathrm{OH}^{*}$ chemiluminescence signal in the $800 \mathrm{~K}$ case barely diverges until the head-vortex of the spray appears around $60 \mathrm{~mm}$ downstream. Spreading angles from non-reacting Schlieren experiments show negligible correlation with the ambient temperature [63]. A decreasing spreading angle downstream of the FLOL indicates that there is a restriction imposed on the high-temperature reactions by the ambient conditions, one possibility being that the mixture at the periphery does not reach the required tempera- 
ture anymore. Again, slightly contrary to the expected radial increase of initial $\mathrm{OH}$ appearance due to the downstream movement of the FLOL in the $800 \mathrm{~K}$ variation, the $\mathrm{OH}$ branches appear relatively close to the spray axis, similar to what has been observed for $\mathrm{OH}^{*}$ chemiluminescence. Based on a well-defined structure below the spray axis there is a decreased amount of laser sheet attenuation in this case as well. Taking both the reduced amount of attenuation and the appearance of $\mathrm{OH}^{*}$ chemiluminescence into account indicates that the PLIF signal detected close to the spray axis originates from ground state $\mathrm{OH}$ radicals. Other possible sources for PLIF signal, apart from a more premixed type of combustion in the central region of the spray, are turbulent transport from the periphery, or the dissociation of $\mathrm{H}_{2} \mathrm{O}$.

The increases in ambient temperature and ambient oxygen concentration show a very similar influence on the structure of the spray flame, although the reaction zone of the high-temperature case appears slightly thinner. An increase in oxygen concentration requires less mixing to attain a stoichiometric mixture fraction, while the fuel-air mixture reaches the required ignition conditions sooner for a higher ambient temperature. Both parameter changes lead to a more reactive mixture, so that the conditions required for auto-ignition are met closer to the nozzle. Therefore, the FLOL decreases and the flame becomes narrower, the latter just because closer to the nozzle the jet is narrower, as indicated by the triangle outlines. Similar to the reduction in injection pressure, the relative intensities of the FLOL region (due to $\mathrm{OH}^{*}$ ) and the soot lobes further downstream appear closer to one another and therefore cannot really be distinguished. An apparent asymmetry in the fluorescence contour along the upper and lower lobes of the $\mathrm{OH}$ distributions can also be observed. The length of the upper lobe increases in the upstream direction due to the decreasing FLOL if either the $\mathrm{O}_{2}$ concentration or ambient temperature is increased, whereas that of the lower lobe decreases in the downstream region. Given that also the soot luminosity moves upstream for these parameter variations, the most likely explanation for this asymmetry is to be found in attenuation of laser light by the central portion of the jet. Since the low soot conditions both show a decreased amount of attenuation, it is expected that PAH and soot are primarily responsible on this account.

Due to the inverse Abel transformation, the line-of-sight data is transformed into spatially resolved data; therefore, the intensity distribution in the images changes. It is such images that can be compared to numerical calculations. For future comparisons, it is recommended to include $\mathrm{OH}^{*}$ mechanisms in models and to compare forward Abel transformed modelling results to experimental $\mathrm{OH}^{*}$ results (or the other way around, as shown in this work). For such comparisons, $\mathrm{OH}^{*}$ results are preferred over $\mathrm{OH}$ PLIF recordings since the show good correspondence, but do not suffer from laser energy dependencies.

The effect of variation of injection pressure was studied at TU/e using the high-speed approach, which allows to construct $I_{x t}$ plots for these cases. The contours for the variations in injection pressure, determined as for Figure 3, are illustrated in Figure 10. Concerning the flame penetration and FLOL, there is only a small difference between 100 and $150 \mathrm{MPa}$ injection pressure, whereas 


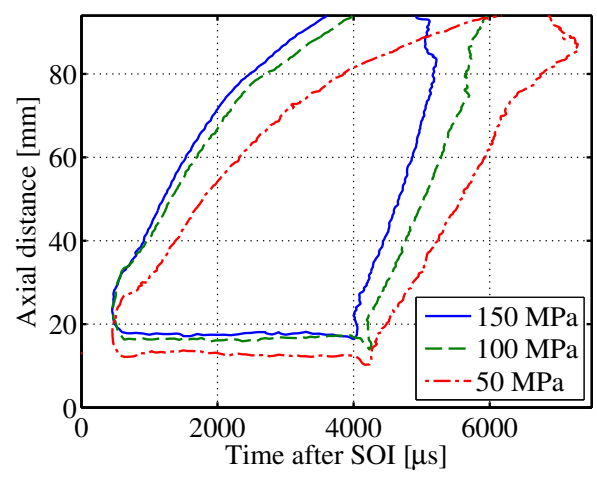

Figure 10: Radially integrated $\mathrm{OH}^{*}$ intensity contours obtained at TU/e for different injection pressures. The contours represent locations with the same intensity as the FLOL, similar to Figure 3.

at $50 \mathrm{MPa}$ the FLOL is smaller and the relative flame penetration is shorter. Injection pressure variations may give rise to slight differences in injection duration and needle closing behavior, which can be observed around $4 \mathrm{~ms}$ aSOI. However, when we study the trailing edge of the flame after the EOI, there is an essentially linear decrease in burn-out flame speed with decreasing injection pressure. This dependence of the entrainment wave on injection pressure is clearly observed in the burn-out phase, and is in agreement with predictions from the 1D spray model [42]. Increasing duration of the burnout phase implies extended time required for soot oxidation. For the two injection pressure variations, the combustion recession phenomenon is more clearly captured with these contours. Since the threshold for the contours are based on the intensity at the FLOL, this sensitivity can be explained by the decreased intensity at the FLOL with respect to the soot cloud downstream, as observed in Figure 9. Another phenomenon is observed for the initial auto-ignition phase of the lowest injection pressure. Where the higher injection pressures seem to stabilize nearly instantly, there is a small decrease of the FLOL during the auto-ignition phase for the case of $50 \mathrm{MPa}$.

\subsubsection{Low-temperature reaction zones}

Parameter studies involving the ambient oxygen concentration and ambient temperature during the quasi-steady phase of the spray, were carried out at IFPEn using $\mathrm{CH}_{2} \mathrm{O}$ PLIF, equivalent to those discussed above for $\mathrm{OH}^{*}$ and OH PLIF. At Sandia, the influence of ambient temperature was studied as well, providing one supplementary low temperature variation and an additional condition to check consistency of the results apart from the Spray A baseline. The temperature variation recordings obtained by Sandia are single shot recordings.

Results for $\mathrm{CH}_{2} \mathrm{O}$ are collected in Figure 11, using the green color channel. Similar to Figure 6, red is used for OH PLIF (when available), and the white contour shows the outline of $\mathrm{OH}^{*}$ chemiluminescence. Green and red arrow- 
IFPEn - O $\%(4700 \mu \mathrm{s})$
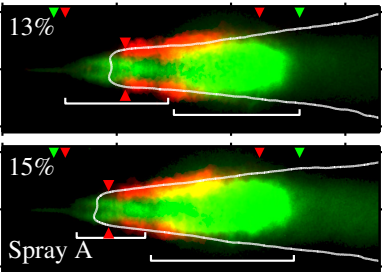

$21 \%$

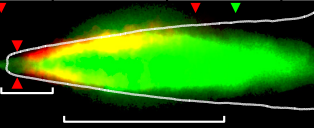

20

40
IFPEn - T $(4700 \mu \mathrm{s})$
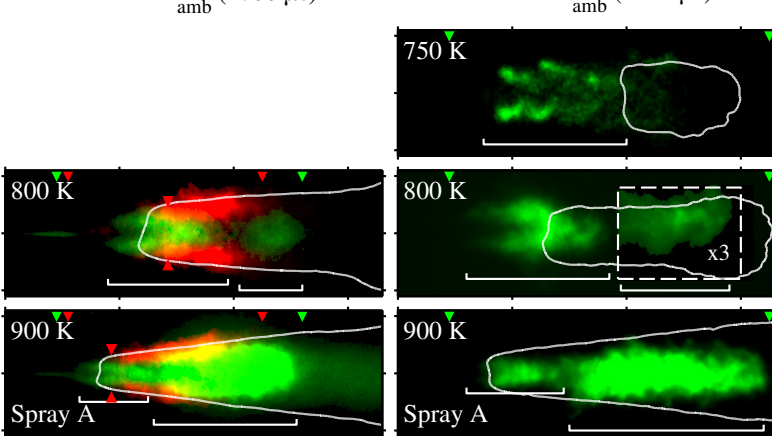

$1000 \mathrm{~K}$

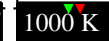

600

\section{.}

0

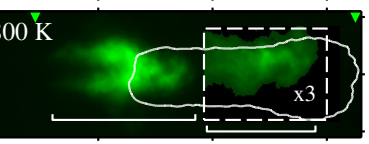

\section{$900 \mathrm{~K}$}

Spray A

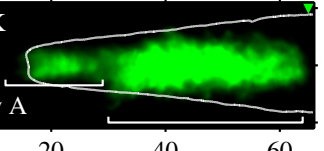

20

40

60

Figure 11: The effect of ambient oxygen concentration and ambient temperature on the results of formaldehyde and PAH fluorescence in green, studied by IFPEn and Sandia. The red color channel is used for OH PLIF results when available, and the white contour depicts the $\mathrm{OH}^{*}$ outline, similar to Figure 6. IFPEn images were recorded at $4700 \mu$ s after SOI, Sandia images at a time of $2700 \mu \mathrm{s}$; both are in the quasi-steady stage of the spray. Sandia images at $750 \mathrm{~K}$ and $800 \mathrm{~K}$ ambient temperature are recorded for a single experiment. Some weak diffuse signal outside the laser sheet and jet boundaries is observed for most variations by IFPEn, similar to Figure Figure 6. See text for additional details.

heads in the top of the figure represent the corresponding laser sheet limits. The red arrowheads at the location with the maximum intensity at the FLOL from Figure 9 are reproduced for the results of IFPEn. Individual regions contributing to the signal detection upon excitation at a wavelength of $355 \mathrm{~nm}$ have been identified by white brackets. In principle, the upstream region is identified as formaldehyde fluorescence, in some cases preceded by light scattering off the liquid fuel. Further downstream the signal is expected to be dominated by PAH fluorescence. A justification for this interpretation can be found in the analysis of (time-resolved) $\mathrm{CH}_{2} \mathrm{O}$ discussed above, and the $\mathrm{OH}^{*}$ chemiluminescence contours. At the location of the FLOL there has not been time, or adequate mixture temperature for soot formation. Only further downstream significant soot luminosity is observed. Fuel is expected to be partly pyrolysed in the region in between, and this is where formaldehyde is expected to be formed, and further downstream followed by growing PAHs. Moreover, $\mathrm{CH}_{2} \mathrm{O}$ is expected to be confined to the spray axis, where little oxygen is available.

Looking at the $\mathrm{O}_{2}$ concentration sweep, the regions of formaldehyde and $\mathrm{PAH}$ can clearly be identified in the low-oxygen image $\left(13 \% \mathrm{O}_{2}\right)$. Although not reproduced here, the formaldehyde structure follows the radial expansion bound by the spray cones illustrated in Figure 9, by the confinement between the $\mathrm{OH}$ branches. On increasing the oxygen concentration, the PAH region 
becomes more prevalent and moves upstream, overlapping with the region where formaldehyde fluorescence would be expected; in the bottom image $\left(21 \% \mathrm{O}_{2}\right)$ the two are hardly distinguishable. Although visible, the $\mathrm{CH}_{2} \mathrm{O}$ signal is relatively low in a more narrow region near the spray axis, although still more prevalent at the location where $\mathrm{OH}$ arises. Reported values for the liquid penetration of the Spray A baseline reach up to $12 \mathrm{~mm}$ downstream of the injector orifice [2-4]. Therefore, it is hard to distinguish between the formaldehyde structure and light scattering off the liquid fuel as well.

Changing the mixture reactivity by varying the ambient gas temperature has a similar effect. At very low temperature ( $750 \mathrm{~K}$; Sandia) there is hardly any expectation for soot precursors since centerline mixture fraction values at the location of the FLOL $(>40 \mathrm{~mm}$ ) have reached near stoichiometric conditions [60]. At a distance relatively far downstream we observe an irregular distribution of formaldehyde, indicating locally igniting pockets of fuel in hotter regions of the mixing layer at the jet periphery. (Take note that this image is a single shot result.) In the center of the spray, temperature is presumably too low for first-stage ignition. At an ambient temperature of $800 \mathrm{~K}$ the formaldehyde distribution is located in the central spray region, and a small cloud of soot precursors is observed further downstream, though the intensity in this region for the results of Sandia have been increased with a factor three to clearly identify $\mathrm{PAH}$, illustrated by the dashed white rectangle. In the IFPEn results at $800 \mathrm{~K}$, $\mathrm{OH}$ and formaldehyde signal appear closer to one another compared the other conditions. Note that there was no significant overlap for the single-shot result displayed in Figure 6. As these results are again ensemble averaged, this is the result of turbulent air entrainment followed by more locally igniting pockets. Upon increasing the temperature further, the PAH fluorescence increases relative to that of formaldehyde, and it grows upstream, until at $1000 \mathrm{~K}$ the two contributions can hardly be separated any more. Similar to the highest oxygen concentration case, formaldehyde is found in a confined region in the vicinity of the FLOL.

Comparing the structures in the images of IFPEn and Sandia at an ambient temperature of $800 \mathrm{~K}$ shows some minor deviations, although it has been shown that these conditions are more prone to fluctuations. The formaldehyde signal obtained by Sandia appears to start slightly upstream compared to the image of IFPEn, but the radial distribution is very similar. The PAH fluorescence indicated by the downstream bracket starts at a similar downstream location for both images. Note that on top of the relative signal intensities, a small deviation in ambient temperature already changes the appearance of $\mathrm{CH}_{2} \mathrm{O}$ and $\mathrm{PAH}$ significantly at these low temperature variations, substantiated by the result of $750 \mathrm{~K}$.

When the regions of $\mathrm{PAH}$ fluorescence are compared with detection of $\mathrm{OH}$ PLIF above and below the spray axis in Figure 11, the relation between soot precursors and laser sheet attenuation is further confirmed. The conditions where PAH fluorescence is dominant, correspond with a large amount of laser sheet attenuation in the OH PLIF results. Similarly, attenuation is less prominent when formaldehyde structures are prevailing. When both $\mathrm{OH}$ and $\mathrm{CH}_{2} \mathrm{O}$ 
PLIF are used, attenuation in the $\mathrm{OH}$ signal can aid in the identification of formaldehyde. As observed in the analysis of the Spray A baseline case, the red arrowheads from Figure 9 are found in the vicinity of the maximum radial width of the formaldehyde signal for all the parametric variations performed by IFPEn.

\section{Summary and conclusions}

Using the dedicated constant-volume spray combustion facilities of participants in the ECN, the quasi-steady and transient flame structures under Spray A conditions and parametric variations thereof have been studied. The chemical species involved include the ground state $\mathrm{OH}$ radical and the low-temperature flame product $\mathrm{CH}_{2} \mathrm{O}$ (using PLIF) and the excited $\mathrm{OH}^{*}$ radical (using spontaneous chemiluminescence). Both spontaneous and laser-induced soot luminosity and PAH fluorescence contribute to the measurements as well. Achieving well-defined, well-known and reproducible conditions, experimental results are compared among institutes and as a function of the parametric variations. The main findings from this study include:

- The results of nominally identical experiments at TU/e, IFPEn and Sandia show good agreement at the Spray A baseline condition for all different diagnostic techniques which have been employed to characterize the flame structures. The small remaining differences between the obtained results have been ascribed to the differences in detection equipment and timing, apart from the spread in thermodynamic conditions. The results are consistent and lend confidence to the subsequent comparisons of timedependent results and the parametric studies performed by individual participating institutes.

- Transient flame structures of the Spray A baseline have been characterized using a high-speed imaging approach for chemiluminescence and various timings for single-shot techniques. The results obtained during these initial stages are more susceptible to the different approaches to achieve the desired boundary conditions, as partly described in previous work [2-4]. In this analysis we identified the auto-ignition, combustion recession after the end of injection, increased velocities of the luminous zone in the burnout phase, and reproducible, high-intensity streaks traveling downstream. The increased velocity in the burn-out phase can be ascribed to the entrainment wave after the EOI, and there is evidence that the high-intensity streaks reflect similar and consistent large-scale structures of soot-burnout during injection.

- Comparing the results obtained by the different diagnostic techniques and additional spray properties which were available by the ECN have aided in the interpretation and description of the low temperature flame structures of the quasi-steady Spray A flame. We identify regions of formaldehyde 
formation downstream of the liquid length in fuel-rich regions with sufficient entrainment of the high-temperature ambient. Subsequently we describe the consumption adjacent to the diffusion flame characterized by the presence of $\mathrm{OH}$ and $\mathrm{OH}^{*}$ at the periphery, and the mixing and interaction with reactants when moving radially inward.

- Evident differences in flame structure have been observed, depending on whether $\mathrm{OH}^{*}$ chemiluminescence or (ground state) OH PLIF is used for visualization. $\mathrm{OH}^{*}$ is found slightly upstream of the earliest evidence of $\mathrm{OH}$, but the distribution of the latter extends to a larger radial distance from the spray axis. This is consistent with the view that $\mathrm{OH}^{*}$ is a reaction-zone chemistry product, with a lifetime ultimately limited by the spontaneous emission rate, whereas $\mathrm{OH}$ is longer lived and in partial equilibrium with the water formed during combustion.

- By studying inverse Abel transformed $\mathrm{OH}^{*}$ chemiluminescence and $\mathrm{OH}$ PLIF of reacting fuel sprays, we have illustrated general trends and shown qualitative influences of variations in injection pressure, ambient oxygen concentration and ambient temperature on the flame structure. There is good agreement between the results of both diagnostic techniques, and peculiarities in $\mathrm{OH}$ signal are related to soot incandescence for the lower injection pressure variations. The reduced amount of OH PLIF signal in the lower branch of parametric variations is related to increasing amounts of PAH and incandescence, increasing the optical thickness in the central region of the spray.

- For future comparison to experimental flame structure, it is recommended to include $\mathrm{OH}^{*}$ kinetic mechanisms in numerical simulations. By transforming either line-of-sight experimental results into planar images, or numerical results to line-of-sight data, relative $\mathrm{OH}^{*}$ intensity and concentrations can potentially be compared.

- Another important finding from high-temperature reaction zones includes the general analogy with a specific spray cone for all the variations studied in this work. Variations which increase the reactivity of the mixture, shift the FLOL location upstream along the spray cone, which narrows the radial extent simultaneously.

- Using general trends and the known location of the FLOL, the formaldehyde structure has been identified for conditions at which its presence is difficult to detect. For an increase in reactivity, the formaldehyde structure is compressed in the axial and radial direction while moving upstream within the spray cone. The reduced area in which formaldehyde can be expected eventually prevents proper distinction with the light scattered of liquid fuel, or PAH fluorescence.

- The ambient temperature variation of $800 \mathrm{~K}$ has proven to be an interesting case, especially downstream of the FLOL region. Upstream of 
the large FLOL region with a relatively high intensity of chemiluminescence, the structure follows the analogy with a spray cone as discussed above. Downstream of the FLOL, however, the radial extent of the hightemperature reactions appears limited and there is some evidence of high temperature reactions near the spray axis. Downstream of the FLOL, there is a definite separation between $\mathrm{CH}_{2} \mathrm{O}$ and $\mathrm{PAH}$, which provides opportunities to study chemical species within this transition, opposed to the limitations observed by increasing reactivity of the mixture.

\section{Acknowledgments}

Experiments presented by TU/e were conducted at the Combustion Technology facility of the Eindhoven University of Technology. The loan of optical filters by IFPEn is highly appreciated, and we thank Hans van Griensven and Theo de Groot for their technical support. For the experiments conducted at IFPEn, we thank Laurent Hermant for his technical assistance. The experiments presented by Sandia were conducted at the Combustion Research Facility, Sandia National

Laboratories, Livermore, CA. Support was provided by the U.S. Department of Energy, Office of Vehicle Technologies. Sandia is a multiprogram laboratory operated by Sandia Corporation, a Lockheed Martin Company, for the United States Department of Energy's National Nuclear Security Administration under contract DE-AC04-94AL85000.

\section{References}

[1] L.M. Pickett, available at http://www.sandia.gov/ECN/.

[2] L.M. Pickett, C.L. Genzale, G. Bruneaux, L. Malbec, et al., Comparison of Diesel Spray Combustion in Different High-Temperature, High-Pressure Facilities, SAE Technical Paper 2010-01-2106.

[3] M. Meijer, L.M.T. Somers, J. Johnson, J. Naber, et al., Engine Combustion Network (ECN): Characterization and Comparison of Boundary Conditions for Different Combustion Vessels, Atomization Spray 22 (9) (2012) 777-806.

[4] M. Bardi, R. Payri, L.M. Malbec, G. Bruneaux, et al., Engine Combustion Network (ECN): Comparison of Spray Development, Vaporization, and Combustion in Different Combustion Vessels, Atomization Spray 22 (10) (2012) 807-842.

[5] A.L. Kastengren, F.Z. Tilocco, C.F. Powell, J. Manin, et al., Engine Combustion Network (ECN): Measurements of Nozzle Geometry and Hydraulic Behavior, Atomization Spray 22 (12) (2012) 1011-1052.

[6] S.A. Skeen, J. Manin, L.M. Pickett, E. Cenker, et al., A Progress Review on Soot Experiments and Modeling in the Engine Combustion Network (ECN), SAE Int. J. Engines 9 (2016) 883-898. 
[7] S. Bhattacharjee, D.C. Haworth, Simulations of transient n-heptane and ndodecane spray flames under engine-relevant conditions using a transported PDF method, Combust. Flame 160 (2013) 2083-2102.

[8] G. D'Errico, T. Lucchini, F. Contino, M. Jangi, et al., Comparison of wellmixed and multiple representative interactive flamelet approaches for diesel spray combustion modelling, Combust. Theor. Model. 18 (2014) 65-88.

[9] L. Zhaoyu, S. Som, S. Mani Sarathy, M. Plomer, et al., Development and validation of an n-dodecane skeletal mechanism for spray combustion applications, Combust. Theor. Model 18 (2014) 187-203.

[10] Y. Pei, E.R. Hawkes, S. Kook, G.M. Goldin, et al., Modelling n-dodecane spray and combustion with the transported probability density function method, Combust. Flame 162 (2015) 2006-2019.

[11] A. Wehrfritz, O. Kaario, V. Vuorinen, B. Somers, Large Eddy Simulation of n-dodecane spray flames using flamelet generated manifolds, Combust. Flame 167 (2016) 113-131.

[12] J.E. Dec, A Conceptual Model of DI Diesel Combustion Based on LaserSheet Imaging, SAE Technical Paper 970873.

[13] D. Siebers, B. Higgins, Flame Lift-Off on Direct-Injection Diesel Sprays Under Quiescent Conditions, SAE Technical Paper 2001-01-0530.

[14] B. Higgins, D. Siebers, Measurement of the Flame Lift-Off Location on DI Diesel Sprays Using OH Chemiluminescence, SAE Technical Paper 200101-0918.

[15] D. Siebers, B. Higgins, L. Pickett, Flame Lift-Off on Direct-Injection Diesel Fuel Jets: Oxygen Concentration Effects, SAE Technical Paper 2002-010890 .

[16] M.P.B. Musculus, Effects of the In-Cylinder Environment on Diffusion Flame Lift-Off in a DI Diese Engine, SAE Technical Paper 2003-01-0074.

[17] G. Bruneaux, Combustion structure of free and wall-impinging diesel jets by simultaneous laser-induced fluorescence of formaldehyde, poly-aromatic hydrocarbons, and hydroxides, Int. J. Eng. Res. 9 (3) (2008) 249-265.

[18] A.J. Donkerbroek, A.P. van Vliet, L.M.T. Somers, N.J. Dam, et al., Relation between hydroxyl and formaldehyde in a direct-injection heavy-duty diesel engine, Combust. Flame 158 (3) (2011) 564-572.

[19] D.C. Oren, S. Wahiduzzaman, C.R. Ferguson, A Diesel Combustion Bomb: Proof of Concept, SAE Technical Paper 841358.

[20] M. Meijer, J. Galle, L.M.T. Somers, J.G.H. Griensven, et al., High-Speed Charracterization of ECN Spray A Using Various Diagnostic Techniques, SAE Int. J. Engines 6 (2) (2013) 1238-1248. 
[21] E. Cenker, G. Bruneaux, L. Pickett, C. Schulz, Study of Soot Formation and Oxidation in the Engine Combustion Network (ECN), Spray A: Effects of Ambient Temperature and Oxygen Concentration, SAE Int. J. Engines 6 (1) (2013) 352-365.

[22] J. Benajes, R. Payri, M. Bardi, P. Martí-Aldaraví, Experimental characterization of diesel ignition and lift-off length using a single-hole ECN injector, Appl. Therm. Eng. 58 (2013) 554-563.

[23] L.M. Pickett, J. Manin, A.L. Kastengren, C.F. Powell, Comparison of NearField Structure and Growth of a Diesel Spray Using Light-Based Optical Microscopy and X-Ray Radiography, SAE Technical Paper 2014-01-1412.

[24] S.A. Skeen, J. Manin, L.M. Pickett, Simultaneous formaldehyde PLIF and high-speed schlieren imaging for ignition visualization in high-pressure spray flames, Proc. Combust. Inst. 35 (2015) 3167-3174.

[25] S.A. Skeen, J. Manin, L.M. Pickett, Visulization of Ignition Processes in High-Pressure Sprays with Multiple Injections of n-Dodecane, SAE Technical Paper 2015-01-0799.

[26] L. Malbec, J. Egúsquiza, G. Bruneaux, M. Meijer, Characterization of a Set of ECN Spray A Injectors: Nozzle to Nozzle Variations and Effect on Spray Characteristics, SAE Technical Paper 2013-24-0037.

[27] M. Meijer, R.J. Christians, J.G.H. van Griensven, L.M.T. Somers, et al., Engine Combustion Network: Implementation and Analysis of Combustion Vessel Spray A Conditions, ILASS-Americas 23rd Annual Conference.

[28] A.G. Gaydon, The Spectroscopy of Flames, Chapman \& Hall, 1957.

[29] A.G. Gaydon, H.G. Wolfhard, Flames, Their Structure, Radiation, and Temperature, Chapman \& Hall, 1979.

[30] L.M. Pickett, available at http://www.sandia.gov/ecn/cvdata/ assets/movies/jkldnAL4movie.php.

[31] J.E. Dec, C. Espey, Chemiluminescence Imaging of Autoignition in a DI Diesel Engine, SAE Technical Paper 982685.

[32] R.J.H. Klein-Douwel, A.J. Donkerbroek, A.P. van Vliet, M.D. Boot, et al., Soot and Chemiluminescence in Diesel Combustion of Bio-Derived, Oxygenated and Reference Fuels, Proc. Combust. Inst. 32 (2) (2009) 2817-2825.

[33] L.M. Pickett, D.L. Siebers, Soot formation in diesel fuel jets near the lift-off length, Int. J. Engine Res. 7 (2) (2006) 103-130.

[34] J. Dec, E. Coy, OH Radical Imaging in a DI Diesel Engine and the Structure of the Early Diffusion Flame, SAE Technical Paper 960831. 
[35] T. Metz, X. Bai, F. Ossler, M. Aldén, Fluorescence lifetimes of formaldehyde (H2CO) in the A1A2 X1A1 band system at elevated temperatures and pressures, Spectrochim. Acta, Part A 60 (2003) 1043-1053.

[36] C.A. Idicheria, L.M. Pickett, Formaldehyde Visualization Near Lift-off Location in a Diesel Jet, SAE Technical Paper 2009-01-1352.

[37] M.P.B. Musculus, P.C. Miles, L.M. Pickett, Conceptual Models for Partially Premixed Low-Temperature Diesel Combustion, Prog. Energy Combust. Sci. 39 (2013) 246-283.

[38] A.J. Donkerbroek, A.P. van Vliet, L.M.T. Somers, N.J. Dam, et al., Timeand space-resolved quantitative LIF measurements of formaldehyde in a heavy-duty diesel engine, Combust. Flame 157 (2010) 155-166.

[39] L.M. Pickett, D.L. Siebers, Soot in diesel fuel jets: effects of ambient temperature, ambient density, and injection pressure, Combust. Flame 138 (2004) 114-135.

[40] C. Koci, G. Martin, T. Bazyn, W. Morrison, et al., The Influence of Diesel End-of-Injection Rate Shape on Combustion Recession, SAE Int. J. Engines 8 (2) (2015) 647-659.

[41] B. Knox, C. Genzale, L. Pickett, J. Garcia-Oliver, et al., Combustion Recession after End of Injection in Diesel Sprays, SAE Technical Paper 201501-0797.

[42] M.P.B. Musculus, K. Kattke, Entrainment Waves in Diesel Jets, SAE Int. J. Engines 2 (1) (2009) 1170-1193.

[43] J. Borée, N. Atassi, G. Charnay, Phase averaged velocity field in an axisymmetric jet subject to a sudden velocity decrease, Exp. Fluids 21 (1996) $447-456$.

[44] M.Y. Choi, K.A. Jensen, Calibration and Correction of Laser-Induced Incandescence for Soot Volume Fraction Measurements, Combust. Flame 112 (1998) 485-491.

[45] C. Espey, J.E. Dec, T.A. Litzinger, D.A. Santavicca, Planar Laser Rayleigh Scattering for Quantitative Vapor-Fuel Imaging in a Diesel Jet, Combust. Flame 109 (1-2) (1997) 65-86.

[46] C.A. Idicheria, L.M. Pickett, Quantitative Mixing Measurements in a Vaporizing Diesel Spray by Rayleigh Imaging, SAE Technical Paper 2007-010647 .

[47] R. Dahms, G.A. Paczko, S.A. Skeen, L.M. Pickett, Understanding the ignition mechanism of high-pressure spray flames, Proc. Combust. Inst. (2016) (in press). 
[48] S.A. Skeen, J. Manin, K. Dalen, L.M. Pickett, Extinction-based Imaging of Soot Processes over a Range of Diesel Operating Conditions, 8th U. S. National Combustion Meeting (2013) paper 070IC-0355.

[49] J. Manin, L. Pickett, S. Skeen, Two-Color Diffused Back-Illumination Imaging as a Diagnostic for Time-Resolved Soot Measurements in Reacting Sprays, SAE Int. J. Engines 6 (2013) 1908-1921.

[50] R. Collin, J. Nygren, M. Richter, M. Aldén, et al., Simultaneous OH- and Formaldehyde-LIF Measurements in an HCCI Engine, SAE Technical Paper 2003-01-3218.

[51] C.A.J. Leermakers, M.P.B. Musculus, In-cylinder soot precursor growth in a low-temperature combustion diesel engine: Laser-induced fluorescence of polycyclic aromatic hydrocarbons, Proc. Combust. Inst. 35 (2015) 30793086.

[52] Z. Li, X. Yu, G. Lequien, T. Lind, et al., Comparison of the Lift-Off Lengths Obtained by Simultaneous OH-LIF and $\mathrm{OH}^{*}$ Chemiluminescence Imaging in an Optical Heavy-Duty Diesel Engine, SAE Technical Paper 2015-242418 .

[53] K. Narayanaswamy, P. Pepiot, H. Pitsch, A chemical mechanism for low to high temperature oxidation of n-dodecane as a component of transportation fuel surrogates, Combust. Flame 161 (4) (2014) 866-884.

[54] J.M. Hall, E. L. Petersen, An optimized kinetics model for $\mathrm{OH}$ chemiluminescence at high temperatures and atmospheric pressures, Int. J. Chem. Kinet. 38 (2006) 714-724.

[55] G.P. Smith, C. Park, J. Luque, A note on chemiluminescence in lowpressure hydrogen and methane-nitrous oxide flames, Combust. Flame 140 (2005) 385-389.

[56] M. Tamura, P. A. Berg, J. E. Harrington, J. Luque, et al., Collisional Quenching of $\mathrm{CH}(\mathrm{A}), \mathrm{OH}(\mathrm{A})$, and $\mathrm{NO}(\mathrm{A})$ in Low Pressure Hydrocarbon Flames, Combust. Flame 114 (1998) 502-514.

[57] C. Bekdemir, L.M.T. Somers, L.P.H. de Goey, J. Tillou, et al., Predicting diesel combustion characteristics with Large-Eddy Simulations including tabulated chemical kinetics, Proc. Combust. Inst. 34 (2013) 3067-3074.

[58] A. Maghbouli, T. Lucchini, G. D'Errico, A. Onorati, et al., Parametric Comparison of Well-mixed and Flamelet n-dodecane Spray Combustion with Engine Experiments at Well Controlled Boundary Conditions, SAE Technical Paper 2016-01-0577.

[59] E. Oldenhof, M.J. Tummers, E.H. van Veen, D.J.E.M. Roekaerts, Ignition kernel formation and lift-off behaviour of jet-in-hot-coflow flames, Combust. Flame 157 (2010) 1167-1178. 
[60] L.M. Pickett, J. Manin, C.L. Genzale, D.L. Siebers, et al., Relationship between diesel fuel spray vapor penetration/dispersion and local fuel mixture fraction, SAE Int. J. Engines 2 (2011) 764-799.

[61] J. Pastor, R. Payri, J. Garcia-Oliver, J. Nerva, Schlieren Measurements of the ECN-Spray A Penetration under Inert and Reacting Conditions, SAE Technical Paper 2012-01-0456.

[62] L.M. Pickett, S. Kook, T.C. Williams, Visualization of Diesel Spray Penetration, Cool-Flame, Ignition, High-Temperature Combustion, and Soot Formation Using High-Speed Imaging, SAE Int. J. Engines 2 (2009) 439459.

[63] J. Naber, D. Siebers, Effects of Gas Density and Vaporization on Penetration and Dispersion of Diesel Sprays, SAE Technical Paper 960034. 